\title{
A transgenic mouse model for HLA-B*57:01-linked abacavir drug tolerance and reactivity
}

\author{
Marco Cardone, ${ }^{1}$ Karla Garcia, ${ }^{1}$ Mulualem E. Tilahun, ${ }^{2}$ Lisa F. Boyd, ${ }^{2}$ Sintayehu Gebreyohannes, ${ }^{1}$ Masahide Yano, ${ }^{1}$ \\ Gregory Roderiquez, ${ }^{1}$ Adovi D. Akue, ${ }^{3}$ Leslie Juengst, ${ }^{1}$ Elliot Mattson, ${ }^{1}$ Suryatheja Ananthula, ${ }^{1}$ Kannan Natarajan, ${ }^{2}$ \\ Montserrat Puig, ${ }^{1}$ David H. Margulies, ${ }^{2}$ and Michael A. Norcross ${ }^{1}$ \\ 'Laboratory of Immunology, Division of Biotechnology Review and Research III (DBRR III), Office of Biotechnology Products (OBP), Office of Pharmaceutical Quality (OPQ), Center for Drug Evaluation \\ and Research (CDER), FDA, Silver Spring, Maryland, USA. '2 Laboratory of Immune System Biology, National Institute of Allergy and Infectious Diseases (NIAID), NIH, Bethesda, Maryland, USA. ${ }^{3}$ Division of \\ Bacterial, Parasitic, and Allergenic Products (DBPAP), Office of Vaccines Research and Review (OVRR), Center for Biologics Evaluation and Research (CBER), US FDA, Silver Spring, Maryland, USA
}

\begin{abstract}
Adverse drug reactions (ADRs) are a major obstacle to drug development, and some of these, including hypersensitivity reactions to the HIV reverse transcriptase inhibitor abacavir (ABC), are associated with HLA alleles, particularly HLA-B*57:01. However, not all HLA-B*57:01+ patients develop ADRs, suggesting that in addition to the HLA genetic risk, other factors may influence the outcome of the response to the drug. To study HLA-linked ADRs in vivo, we generated HLA-B*57:01-Tg mice and show that, although $A B C$ activated Tg mouse $C D 8^{+} T$ cells in vitro in a HLA-B*57:01-dependent manner, the drug was tolerated in vivo. In immunocompetent $\mathrm{Tg}$ animals, $\mathrm{ABC}$ induced $\mathrm{CD}^{+} \mathrm{T}$ cells with an anergy-like phenotype that did not lead to $A D R s$. In contrast, in vivo depletion of $C D 4^{+} T$ cells prior to $A B C$ administration enhanced $D C$ maturation to induce systemic ABC-reactive CD8 ${ }^{+}$T cells with an effector-like and skin-homing phenotype along with CD8+ infiltration and inflammation in drug-sensitized skin. B7 costimulatory molecule blockade prevented CD8+ $T$ cell activation. These Tg mice provide a model for $A B C$ tolerance and for the generation of HLA-B*57:01-restricted, ABC-reactive CD8 ${ }^{+} T$ cells dependent on both HLA genetic risk and immunoregulatory host factors.
\end{abstract}

\section{Introduction}

Adverse drug reactions (ADRs) have been defined by the World Health Organization (WHO) as noxious and unintended responses to a drug given at a dose established for the prophylaxis, diagnosis, or therapeutic treatment of a disease. ADRs include a group of immune-mediated adverse side effects referred to as drug hypersensitivity reactions (DHRs) or drug allergies. DHRs are often unpredictable (idiosyncratic) and reveal a broad range of symptoms from mild to severe, occasionally leading to death from drug-induced liver injury (DILI), Stevens-Johnson syndrome (SJS), or toxic epidermal necrolysis (TEN). The systemic inflammatory condition is complex, but drug-reactive $\mathrm{T}$ cells play a major role. Such DHRs represent a major obstacle to the success of a therapeutic drug, both during its development and postmarket surveillance, as well as a global economic burden for public health. The recognition that certain DHRs are associated with alleles of the HLA class I and/or II molecules (1) provided some insight into the mechanisms of the immunopathogenesis of these reactions. However, many details of the mechanism of DHRs in patients are still unknown.

\section{Related Commentary: p. 2746}

Authorship note: MP and MAN are co-senior authors. Conflict of interest: The authors have declared that no conflict of interest exists. Submitted: December 18, 2017; Accepted: March 20, 2018 Reference information: J Clin Invest. 2018;128(7):2819-2832. https://doi.org/10.1172/JCI99321
HLA-B ${ }^{\star} 57: 01$ has been shown to be linked to several ADRs, initially to hypersensitivity reactions to the HIV reverse transcriptase inhibitor guanosine analog abacavir $(\mathrm{ABC})(2,3)$, and subsequently to DILI caused by the penicillin $\beta$-lactam antibiotic flucloxacillin (4) or the antitumor tyrosine kinase inhibitor pazopanib (5). ABC hypersensitivity reaction (AHR) is a severe multisystem syndrome reported in ABC-treated HIV-infected individuals within 6 weeks of treatment (median time to onset of 8 days). Clinical symptoms can include skin rash, fever, malaise, and gastrointestinal disorders (6). Skin biopsies from $\mathrm{AHR}$ rashes and from positive $\mathrm{ABC}$ patch tests show a mixture of infiltrating $\mathrm{CD}^{+}$and $\mathrm{CD}^{+}{ }^{+} \mathrm{T}$ lymphocytes (7), whereas drugexposed but tolerant patients have negative patch tests. Peripheral blood cells from ABC-hypersensitive individuals rapidly respond to the drug in vitro by releasing high levels of TNF or IFN- $\gamma$ compared with levels seen in cells from $\mathrm{ABC}$-tolerant subjects $(8,9)$ and were found to be $\mathrm{CD}^{+} \mathrm{T}$ lymphocytes $(8,10)$. ABC-responsive $\mathrm{CD} 8^{+} \mathrm{T}$ cells are also present in drug-naive HLA-B ${ }^{\star} 57: 01^{+}$donors (10-14). These cells originate from both naive and memory $\mathrm{CD} 8^{+} \mathrm{T}$ lymphocytes, do not require the help of $\mathrm{CD} 4^{+} \mathrm{T}$ cells, and show proliferative capacity and cytokine production when stimulated in vitro.

Of note, AHR has been addressed by the US FDA in the FDA Alert of July 24, 2008 (15), which recommended the screening of patients for HLA-B ${ }^{*}$ 7:01 before initiating or resuming treatment with $\mathrm{ABC}$ or $\mathrm{ABC}$-containing medications. Nevertheless, the extraordinary specificity of AHR for the HLA risk allele, with $100 \%$ of AHR patients being confirmed as HLA-B ${ }^{\star} 57: 01^{+}(16$, $17)$, made $A B C$ an excellent candidate for studying the mechanisms responsible for HLA-associated ADRs. Several laborato- 
A

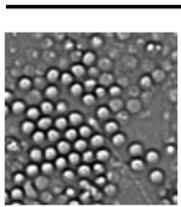

None
$B^{*} 57: 01$

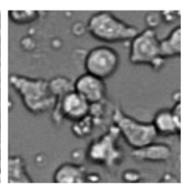

$A B C$

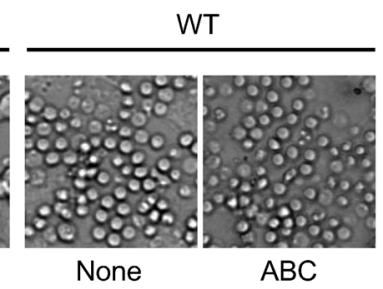

C

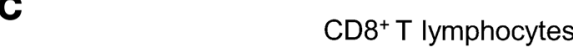

B

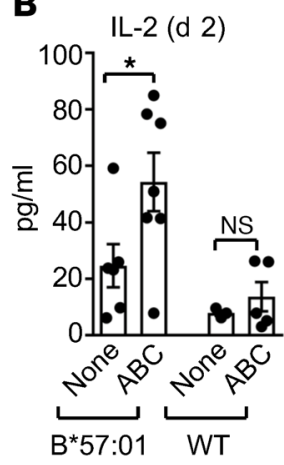

GZB (d 5)

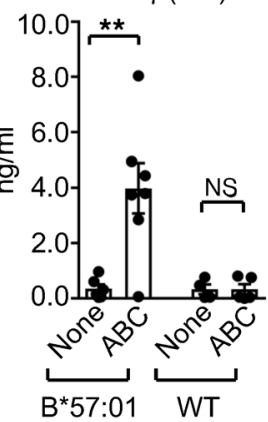

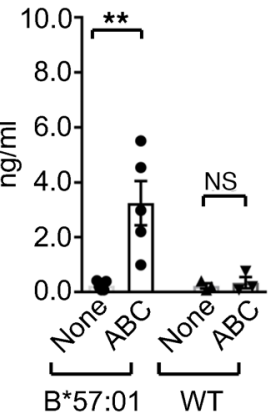

D

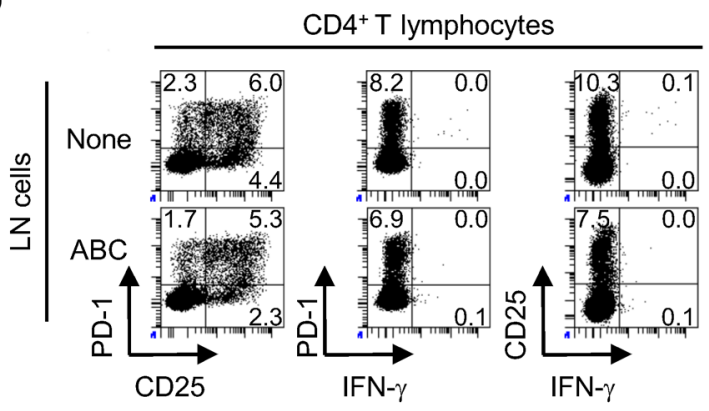

E

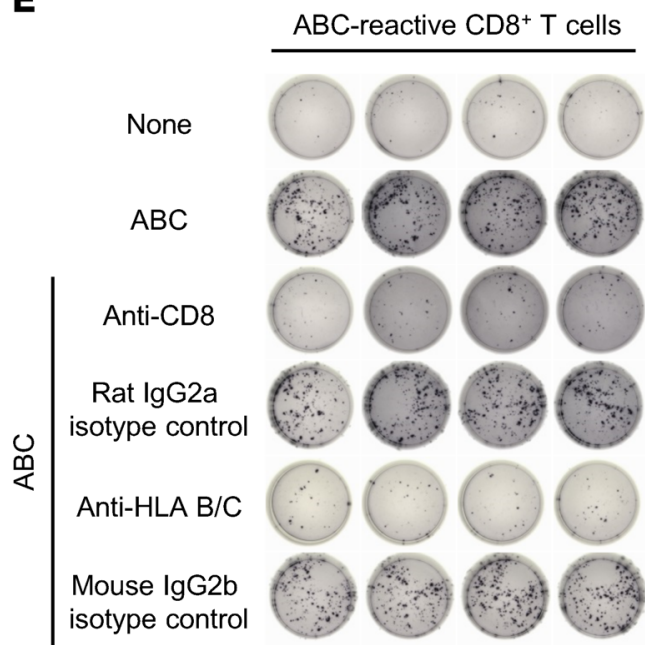

Figure 1. ABC activates Tg mouse CD8 ${ }^{+}$T cells in vitro in an HLA-B*57:01-dependent manner. Cultures of purified splenic CD8+ $T$ cells and cultures of total LN cells from drug-naive HLA-B*57:01-Tg (B*57:01) or WT mice. (A) Bright-field microscopy images (original magnification, $\times 10)$ of purified CD8+ T cells on day 5 of culture. Data are from 1 of 3 representative experiments. (B) IL-2, IFN- $\gamma$, and granzyme B (CZB) in supernatants of purified CD8 ${ }^{+}$T cells at the indicated time of culture. Data represent the mean \pm SEM of ELISA results. Dots indicate the averages of technical replicates in each condition within individual experiments ( $n=3-7$ experiments). (C and D) Percentage of PD- $1^{+}$, CD25+, and IFN- $\gamma^{+}$cells within CD8 ${ }^{+}$(C) and CD4+ (D) T Iymphocytes in Tg purified CD8 ${ }^{+}$T cells and total LN cells cultured for 5 days. Flow cytometric data are from 1 of 2 representative experiments. (E) IFN- $\gamma$ release by ABC-reactive CD8 ${ }^{+}$T cells restimulated with $5 \mu \mathrm{g} / \mathrm{ml} \mathrm{ABC}$, in the absence or presence of the specified mAb, following 14 days of primary stimulation. IFN- $\gamma$ enzyme-linked immunosorbent spot (ELISpot) data show 4 replicates per condition from 1 of 3 representative experiments. ${ }^{*} P<0.05$ and ${ }^{*} P<0.005$, by unpaired, 2 -tailed Student's $t$ test. None, no drug.

ries, including our own, described the interaction of $A B C$ with HLA-B ${ }^{\star} 57: 01$ and characterized the altered repertoire of selfpeptides bound by this HLA allele (18-20). These results prompted models for autoimmunity, in which $A B C$ favored the loading of novel self-peptides containing carboxyl-terminal valine, isoleucine, or leucine into HLA-B ${ }^{\star} 57: 01$. Crystal structures of peptide-HLA-B ${ }^{\star 57: 01}$ complexes with $\mathrm{ABC}$ revealed drug bound in the vicinity of the F pocket of the HLA groove beneath the peptide (19-21). These structural results, however, failed to explain why, while $100 \%$ of HLA-B ${ }^{*} 57: 01^{+}$human $\mathrm{T}$ cell cultures from drug-naive donors respond to $\mathrm{ABC}(13)$, only $55 \%$ of individuals carrying HLA-B ${ }^{\star 57: 01}$ develop AHR $(16,17)$. These findings suggest that, in addition to the HLA genotype, patient- specific conditions may determine the outcome of responses to ABC. The immune system of an HIV-infected individual can be shaped by the virus itself and by secondary effects from infection. HIV, which mainly targets $\mathrm{CD} 4^{+} \mathrm{T}$ cells, can induce innate and adaptive immune activation and inflammation, which can also persist during antiretroviral treatment (22).

Activation of T cells is controlled by regulatory elements such as immune receptors and Tregs. Inhibitory receptors including PD-1, CTLA-4, LAG3, TIM3, and TIGIT can be coexpressed at different levels and in various combinations by reactive CD8 ${ }^{+} \mathrm{T}$ lymphocytes and play a central role in maintaining $\mathrm{T}$ cell homeostasis, self-tolerance, and control of immune responses in cancer and chronic viral infections $(23,24)$. Tregs ensure peripheral immune 
A

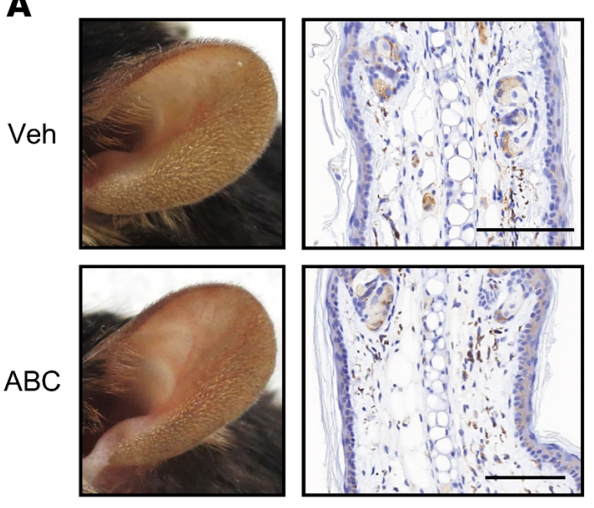

B

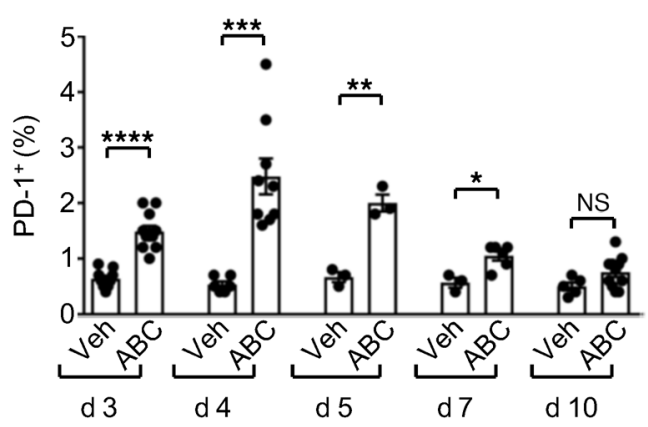

C

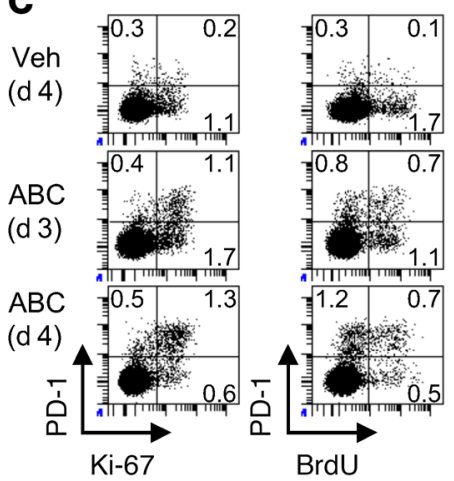

D

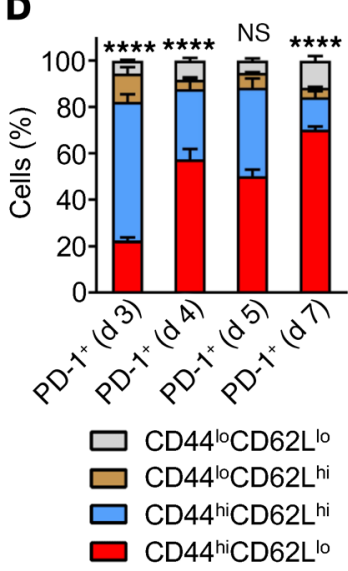

E

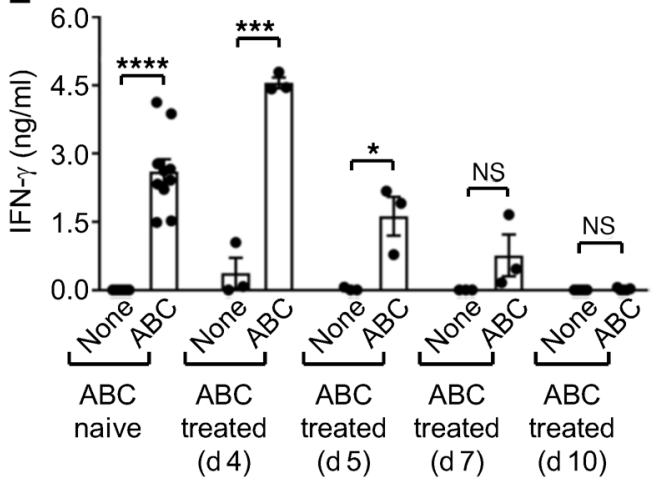

$\mathbf{F}$

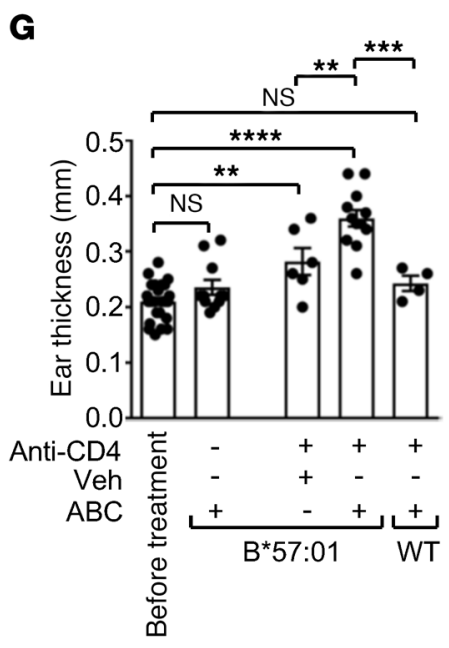

H

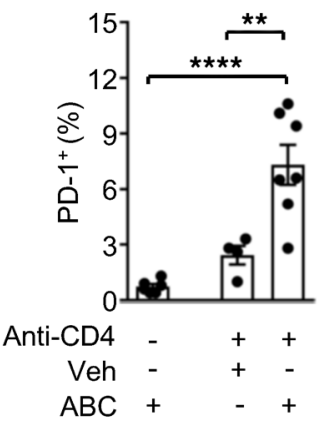

Figure 2. CD4 ${ }^{+} \mathrm{T}$ cells prevent $\mathrm{ABC}$ drug reactivity in HLA-B*57:01-Tg mice. HLA-B*57:01-Tg or WT mice were treated systemically (i.p. injection) and topically (ear painting) with vehicle (Veh) or ABC, in the absence or presence of a CD4depleting mAb. (A) Photos of ears (left) and CD8 $\alpha$ staining of ear sections (IHC, right) from Tg mice treated for 3 weeks. Data are representative of 2 independent experiments. (B) Percentage of PD-1+ cells within $\mathrm{CD} 8^{+} \mathrm{T}$ lymphocytes in the LNs of treated Tg mice, as measured by flow cytometry. (C) Percentage of PD-1+, $\mathrm{Ki}-67^{+}$, and $\mathrm{BrdU}^{+}$cells within $\mathrm{CD} 8^{+} \mathrm{T}$ lymphocytes in the $\mathrm{LNs}$ of treated $\mathrm{Tg}$ mice. Flow cytometric data are from 1 of 2 experiments. (D) Percentage of CD44- and CD62L-expressing cells within CD8 ${ }^{+} \mathrm{PD}-1^{+} \mathrm{T}$ lymphocytes in the LNs of ABCexposed Tg mice, as measured by flow cytometry. $n=3-6$ mice per time point. Statistics refer to the comparison of CD44 ${ }^{\text {hi }} \mathrm{CD} 62 \mathrm{~L}^{\text {hi }}$ versus CD44 $4^{\text {hi }} \mathrm{CD} 62 \mathrm{~L}^{10}$ cells. (E) IFN- $\gamma$ in supernatants from day 5 cultures of $\mathrm{CD} 8^{+} T$ cells from the $L N s$ of $A B C-$ naive or -treated Tg animals, as measured by ELISA. (F) Photos of ears (left) and CD8 $\alpha$ staining of ear sections (IHC, right) from CD4-depleted Tg mice treated for 3 weeks. Data are representative of 2 independent experiments. (C) Ear thickness at week 3 of treatment. (H) Percentage of PD-1+ $1^{+}$cells within CD8 ${ }^{+}$T lymphocytes in the LNs of Tg mice, as measured by flow cytometry at day 10 of treatment. Animals in the $A B C$ control group were also included in the $A B C$ (day 10) group in B. Scale bars: $100 \mu \mathrm{m}$. Data represent the mean $\pm \mathrm{SEM}$. Dots indicate values for individual mice from each group: $n=3-11$ (B); $n=3-10(\mathbf{E}) ; n=4-12$ (C); $n=4-7$ (H). ${ }^{*} P<0.05$, ${ }^{* *} P<0.005$, ${ }^{* *} P<0.0005$, and ${ }^{* * * *} P<0.0001$, by unpaired, 2 -tailed Student's $t$ test (B and $\mathbf{E}$ ), 2-way ANOVA (D), or 1-way ANOVA ( $\mathbf{G}$ and $\mathbf{H}$ ) with Tukey's multiple comparisons correction. None, no drug. tolerance by suppressing reactive $\mathrm{T}$ lymphocytes through various mechanisms such as the maintenance of DCs in an immature state (25). The ability of $\mathrm{CD} 4^{+}$Tregs to affect the optimal costimulation of reactive lymphocytes has been shown to be crucial for preventing autoimmunity. The role of immune receptors, regulatory cells, and costimulation in influencing the outcome of the response to a drug, however, has not yet been addressed in patients or in in vivo animal models of DHR.
Here, we generated and exploited a Tg mouse model for HLA-B ${ }^{*}$ 57:01-restricted ABC tolerance and reactivity. We show that although $\mathrm{CD}^{+} \mathrm{T}$ lymphocytes from drug-naive $\mathrm{Tg}$ mice were rapidly activated in vitro by $\mathrm{ABC}, \mathrm{Tg}$ animals tolerated the drug in vivo. In immunocompetent $\mathrm{Tg}$ mice, $\mathrm{ABC}$ induced a transient response in lymphoid organs that was characterized by the stimulation of reactive $\mathrm{CD} 8^{+} \mathrm{T}$ cells displaying an anergy-like phenotype that did not lead to ADR. In contrast, depletion of $\mathrm{CD} 4^{+} \mathrm{T}$ lympho- 
A

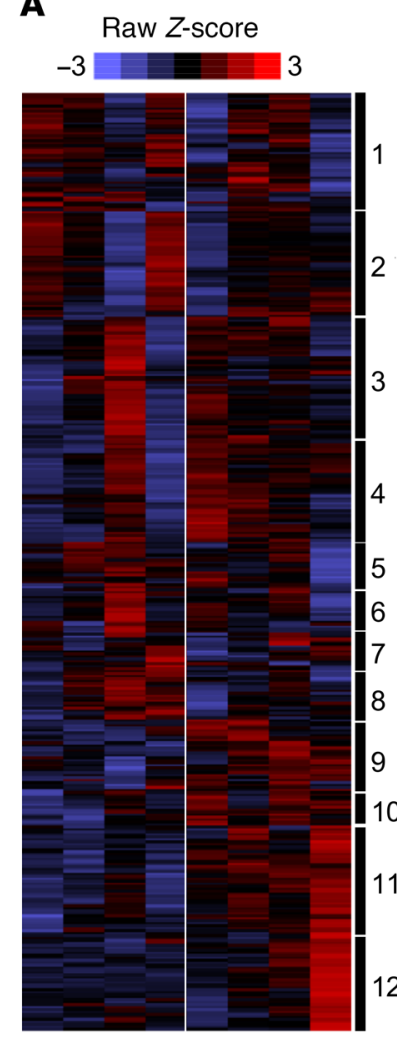

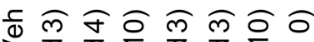

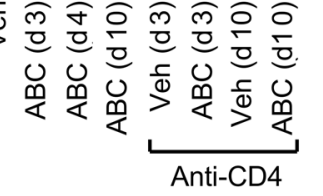

B

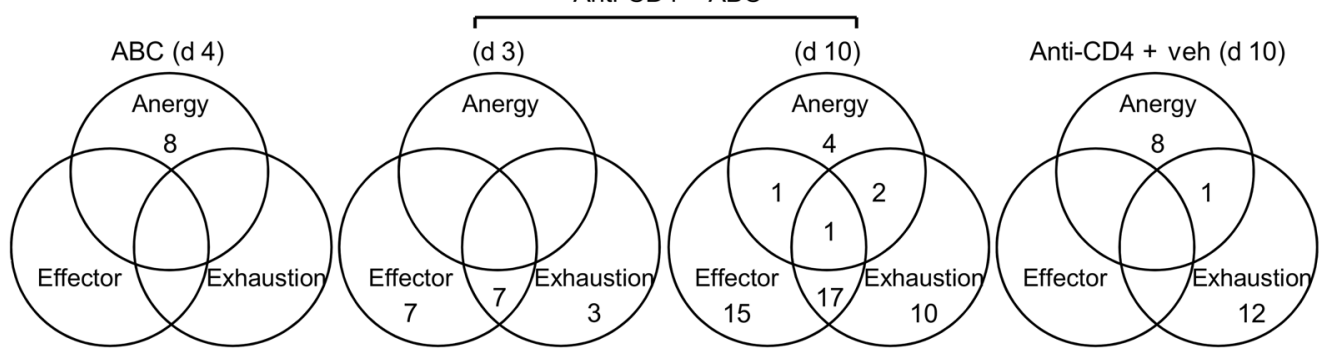

C

Clusters 3,4 , and 6

D

Clusters 11 and 12
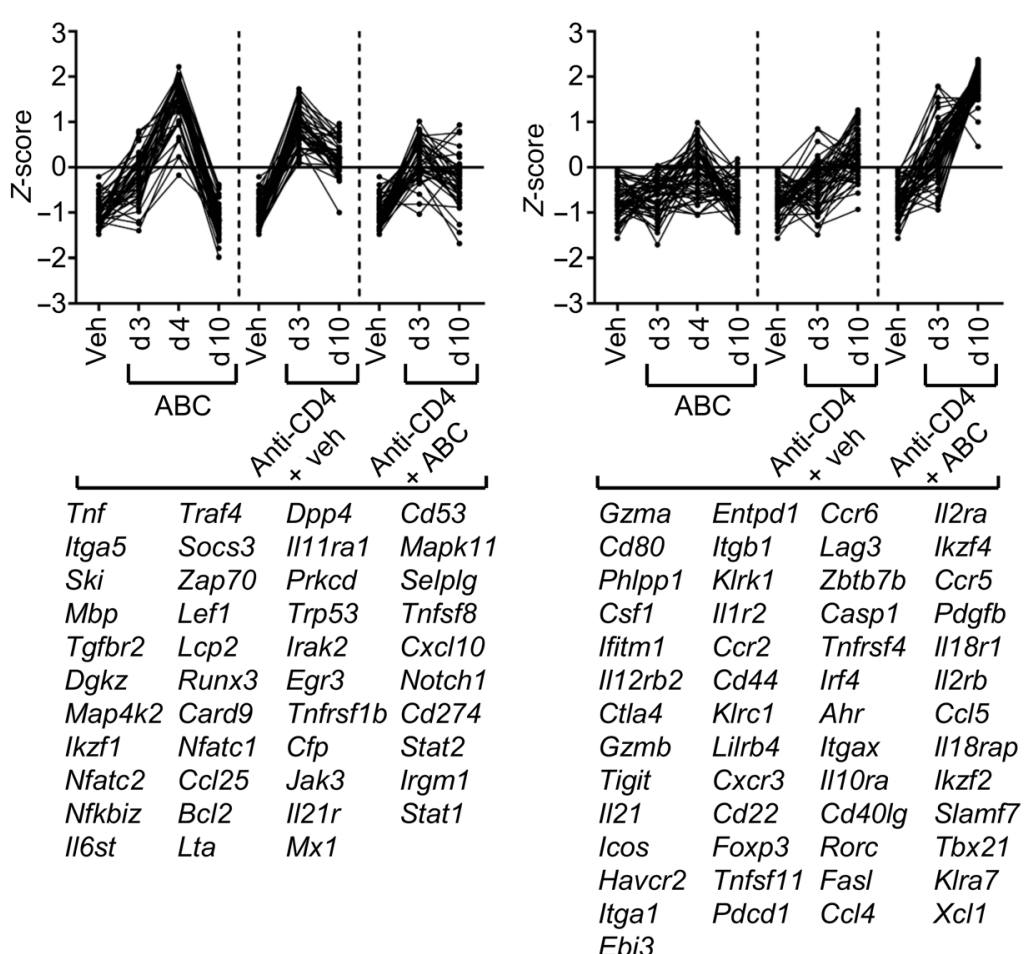

Figure 3. Transcriptional framework of sorted CD8 $^{+} T$ cells from treated HLA-B*57:01-Tg mice. Gene expression analysis of $C D 8^{+} T$ cells sorted from $L N s$ of treated Tg animals. (A) Heatmap shows Z-score-transformed expression values of genes selected as specified in the Methods. Data from individual mice within each group of 5 independent experiments were collapsed prior to gene clustering. (B) Venn diagrams show the number of genes within the leading edge of the gene signatures of the GSEA in Supplemental Figure 6. Genes were counted once, independently of their appearance in multiple signatures. Empty areas indicate an absence of genes. (C and $\mathbf{D})$ Representative gene clusters from the heatmap in $\mathbf{A}$. Listed genes are those significantly upregulated $(P<0.05)$, with a fold-change of 1.5 or greater and with normalized RNA counts above the geometric mean \pm 3 SD of the negative controls, in at least 1 treatment group as compared with vehicle (veh) (see also Supplemental Tables 1-3).

cytes induced a break in immune tolerance, possibly by enhancing antigen-presenting cell (APC) costimulation, leading to a $\mathrm{T}$ cell effector state necessary for the development of ADR.

\section{Results}

$C D 8^{+} T$ cells from drug-naive $H L A-B{ }^{*} 57: 01-T g$ mice are activated by $A B C$ in vitro. To study the mechanisms behind the development of HLA-B*57:01-linked ADRs in vivo, we generated a Tg mouse expressing a chimeric HLA-B ${ }^{*} 57: 01$ molecule under the control of the promoter of the mouse MHC class I gene, $\mathrm{H} 2-\mathrm{K}^{\mathrm{b}}$ (see Methods). The chimeric protein contains the human $\alpha 1$ and $\alpha 2$ domains of the risk allele HLA-B ${ }^{\star} 57: 01$ and the mouse $\alpha 3$ domain of the MHC class I, H2- ${ }^{d}$. The H2- ${ }^{d} \alpha 3$ was inserted to facilitate the interaction of the HLA-B ${ }^{\star} 57: 01$ with the mouse coreceptor CD8 (ref. 26 and our unpublished observations, and Supplemental Figure $1 \mathrm{~A}$; supplemental material available online with this article; https://doi.org/10.1172/JCI99321DS1). We verified the expression of HLA-B ${ }^{\star} 57: 01$ as well as of the $\mathrm{H} 2-\mathrm{D}^{\mathrm{d}} \alpha 3$ subunit by flow cytometry in lymphoid organs and cells, including $\mathrm{CD} 4^{+} \mathrm{T}$ cells, $\mathrm{CD}^{+} \mathrm{T}$ cells, and $\mathrm{B} 22 \mathrm{O}^{+} \mathrm{CD} 19^{+} \mathrm{B}$ cells from the blood of $\mathrm{Tg}$ and WT mice (Supplemental Figure 1B and Supplemental Figure 2).

We first evaluated the responsiveness of HLA-B ${ }^{*} 57: 01-\mathrm{Tg}$ mice to $A B C$ in vitro by monitoring morphological changes, secretion of effector molecules, and expression of cell-surface activation markers in drug-exposed $\mathrm{T}$ lymphocytes (Figure 1). Splenic $\mathrm{CD} 8^{+} \mathrm{T}$ cells from drug-naive $\mathrm{Tg}$ animals were left untreated or stimulated with $\mathrm{ABC}$ for 5 days in the presence of $\mathrm{ABC}$-pulsed irradiated Tg splenocytes. In some experiments, $\mathrm{T}$ cells were then expanded for up to 
A

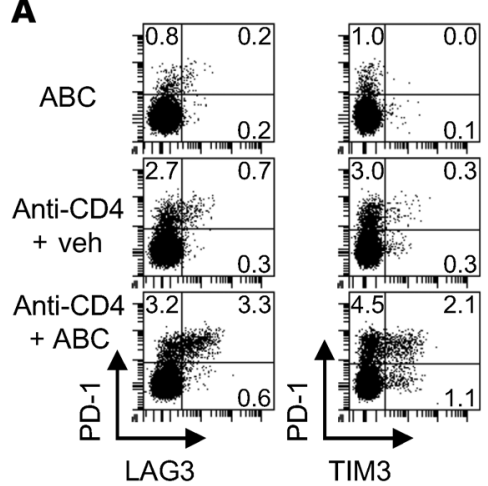

C

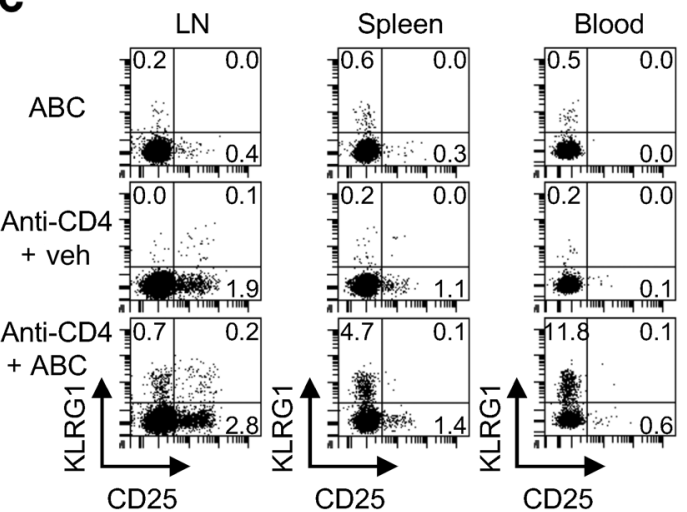

B

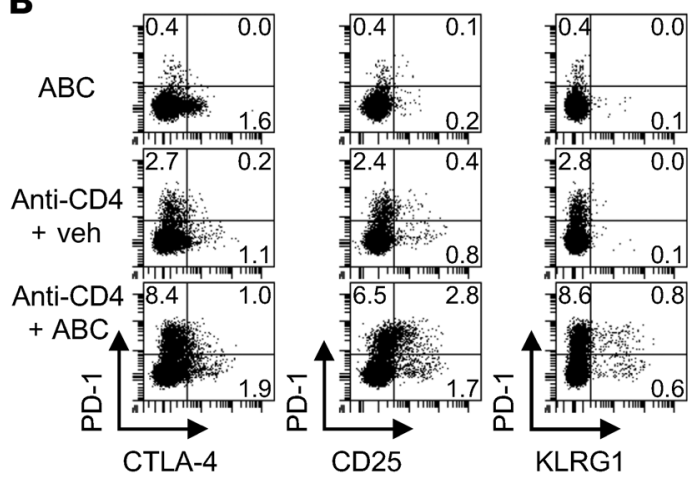

D

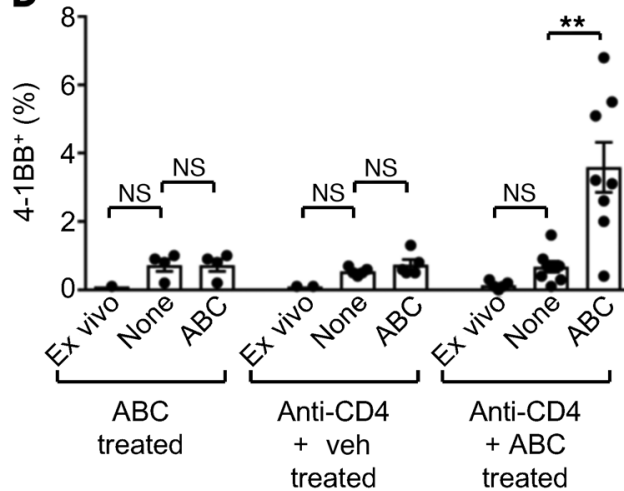

Figure 4. CD8 ${ }^{+} T$ cells of antiCD4 plus ABC Tg mice are enriched for reactive cells at different states of activation. (A-C) Flow cytometric analysis of dysfunction and activation molecules in CD8 ${ }^{+} \mathrm{T}$ cells from LNs of Tg animals on day 10 of treatment ( $\mathbf{A}$ and $\mathbf{B}$ ) and from LNs, spleen, and blood of mice treated for 3 weeks (C). Numbers are a percentage of the positive cells within CD8 ${ }^{+}$T lymphocytes. Data are from 2 experiments (A), 1 of 3 experiments (B), and 1 of 2 experiments (C). (D) Percentage of $4-1 \mathrm{BB}^{+}$cells within $\mathrm{CD} 8^{+} \mathrm{T}$ lymphocytes from the spleens of Tg mice treated for 3 weeks. Splenocytes were analyzed ex vivo and after overnight culture without (None) or with $A B C$ treatment. Data represent the mean \pm SEM. Dots indicate values for individual mice ( $n=4-8$ per group). ${ }^{*} P<0.005$, by 1-way ANOVA with Tukey's multiple comparisons correction. Veh, vehicle.
14 days with IL-2. CD8 ${ }^{+} \mathrm{T}$ cell cultures from drug-naive WT mice were used as controls. ABC-treated cells from $\mathrm{Tg}$, but not WT, animals acquired the morphology of activated $\mathrm{T}$ lymphocytes and released low but significant levels of IL-2 (by day 2) as well as large amounts of IFN- $\gamma$ and granzyme B within 5 days of exposure to the drug (Figure 1, $\mathrm{A}$ and $\mathrm{B}$ ). ABC-reactive $\mathrm{CD} 8^{+} \mathrm{T}$ cells were generated from both purified splenic $\mathrm{CD}^{+} \mathrm{T}$ lymphocytes and pooled lymph node (LN) cells. These cells expressed higher levels of activation markers (PD-1 and IL-2R $\alpha$ subunit [CD25]) than did the cells left untreated. Moreover, approximately $20 \%$ of PD $-1^{+}$and CD $25^{+}$drugresponsive $\mathrm{T}$ cells produced IFN- $\gamma$ (Figure $1 \mathrm{C}$ ). $\mathrm{CD}^{+} \mathrm{T}$ lymphocytes, unlike $\mathrm{CD}^{+}$lymphocytes, did not show the same activation phenotype (Figure 1D), suggesting that $\mathrm{ABC}$-induced immune responses in HLA-B ${ }^{*} 57: 01-\mathrm{Tg}$ mice are mediated by drugreactive $\mathrm{CD}^{+} \mathrm{T}$ cells, consistent with findings reported in both HLA-B ${ }^{\star} 57: 01^{+}$ABC-hypersensitive patients and normal donors (8, 10-14). Next, we verified that the response to $A B C$ in $\mathrm{Tg}$ animals was CD8 and HLA-B ${ }^{\star 57: 01 ~ d e p e n d e n t ~ b y ~ u s i n g ~ n e u t r a l i z i n g ~ A b s ~}$ against mouse CD8 (anti-CD8) or HLA B/C (anti-HLA B/C) (Figure $1 \mathrm{E})$. Release of IFN- $\gamma$ was observed only in cultures of drugresponsive $\mathrm{CD}^{+} \mathrm{T}$ cells restimulated with $\mathrm{ABC}$ and was inhibited in the presence of anti-CD8- or anti-HLA B/C-neutralizing Abs.

Overall, these results demonstrated that the spleens and LNs of drug-naive HLA-B ${ }^{\star} 57: 01-\mathrm{Tg}$ mice contained drug-reactive $\mathrm{CD}^{+} \mathrm{T}$ lymphocytes with effector potential that could rapidly respond to $\mathrm{ABC}$ stimulation in vitro. In addition, expanded drug-reactive $C D 8^{+} \mathrm{T}$ cells could rapidly respond to $\mathrm{ABC}$ stimulation in a HLA-B ${ }^{\star 57: 01-d e p e n d e n t ~ m a n n e r . ~}$

$H L A-B^{*} 57: 01-T g$ mice tolerate $A B C$ in vivo. Motivated by the results obtained in vitro, and with the aim of dissecting the immune events leading to AHR, we next tested the effects of ABC exposure in vivo. We injected $A B C$ i.p. and applied it topically on the ears of $\mathrm{Tg}$ mice for up to 4 weeks (Supplemental Figure 3A), simulating a time frame within which drug-allergic patients report adverse reactions (6). We found that ABC-treated Tg animals showed no signs of skin hypersensitivity. Scarring or dermal/epidermal infiltration by $\mathrm{CD}^{+} \mathrm{T}$ cells was not observed in the drug- or vehicle-exposed mice after a 3-week treatment period (Figure 2A and Supplemental Figure 4). These results raised the question of the potential role of immunosuppressive mechanisms driven by coinhibitory molecules and/or immunosuppressive cells in preventing AHR.

Therefore, we measured the expression of coinhibitory receptors on $\mathrm{CD}^{+} \mathrm{T}$ cells from LNs of ABC-exposed Tg mice throughout the 10 days of drug administration. With the exception of PD-1 (Figure 2B) and weak expression of LAG3 (data not shown), none of the other inhibitory molecules or activation markers examined was detected, including CTLA-4, TIM3, CD25, KLRG1, or cutaneous lymphocyte-associated antigen (CLA) (data not shown). CD ${ }^{+} \mathrm{PD}-1^{+} \mathrm{T}$ cells accumulated during the first 7 days of treatment in the LNs of animals exposed to ABC, unlike those treated with vehicle, peaking at day 4 (Figure $2 \mathrm{~B}$ ). By day 3 , these reactive $\mathrm{T}$ cells showed proliferative capacity, as evidenced by expression of the proliferation marker Ki-67 and by incorporation of BrdU (Figure 2C). Responding $\mathrm{T}$ cells had a predominant $\mathrm{CD} 44{ }^{\mathrm{hi}} \mathrm{C}$ D62 $\mathrm{L}^{\mathrm{hi}}$ memory-like phenotype that rapidly evolved into activated $\mathrm{CD} 44^{\text {hi }} \mathrm{CD} 62 \mathrm{~L}^{\text {lo }}$ cells over time (Figure 2D). These data indicated that the response to $\mathrm{ABC}$ in $\mathrm{HLA}-\mathrm{B}^{\star} 57: 01-\mathrm{Tg}$ mice may have originated from preexisting memory $\mathrm{CD}^{+} \mathrm{T}$ lymphocytes, as reported in humans $(13,14)$. By day 7 , the proportion of drug-reactive $\mathrm{CD} 8^{+} \mathrm{PD}-1^{+} \mathrm{T}$ cells from ABC-stimulated $\mathrm{Tg}$ animals decreased, 
A

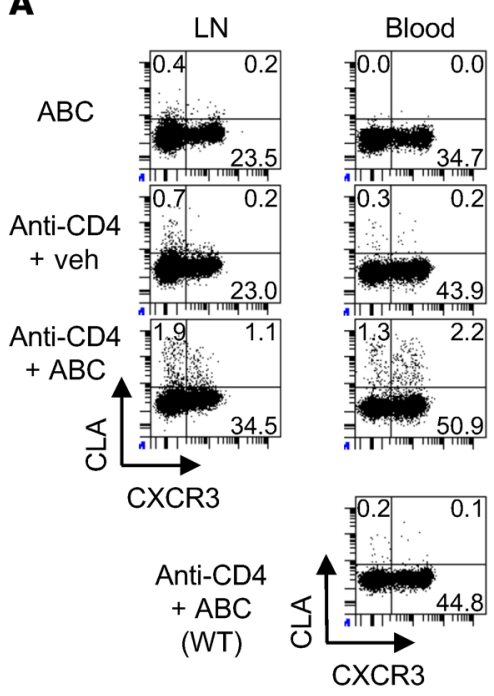

B

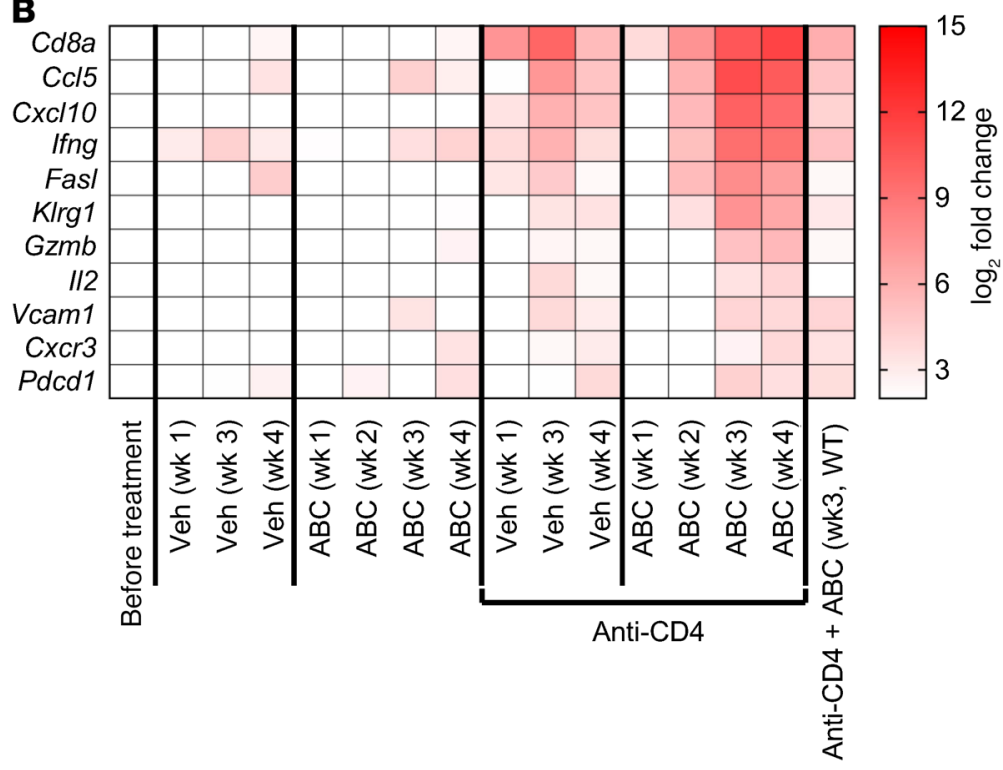

Figure 5. Anti-CD4 plus ABC Tg mice show skin inflammation and CD8 ${ }^{+} \mathbf{T}$ cells expressing skin-homing molecules. (A) Percentage of CLA ${ }^{+}$and CXCR3 ${ }^{+}$cells within CD8+ T lymphocytes in LNs and blood from mice treated for 10 days. Flow cytometric data are from 1 of 2 representative experiments. (B) Expression of inflammatory genes by real-time PCR in skin biopsies of the ears of mice treated for the indicated durations. Data for individual animals within a treatment group and time point from 6 independent experiments were collapsed prior to log transformation. All mice were Tg unless otherwise indicated. Veh, vehicle.

reaching basal levels by day 10 (Figure 2B). ABC-experienced $\mathrm{CD}^{+} \mathrm{T}$ lymphocytes released similar or greater amounts of IFN- $\gamma$ compared with drug-naive $\mathrm{CD}^{+} \mathrm{T}$ cells after in vitro restimulation with $\mathrm{ABC}$, but only when isolated from the LNs of Tg animals treated with the drug for 4 to 5 days (Figure 2E). These data suggested that, in vivo, ABC-reactive $\mathrm{CD} 8^{+} \mathrm{T}$ cells rapidly became unresponsive or were deleted. To determine whether PD-1 restrained drug-reactive cells, HLA- ${ }^{*} 57: 01-T g$ mice were exposed to $\mathrm{ABC}$ in the presence of a neutralizing anti-PD-1 mAb. Anti-PD-1 mAb treatment neither significantly increased the percentage of $\mathrm{CD}^{+} \mathrm{T}$ lymphocytes expressing KLRG1 and CLA (Supplemental Figure 5), nor predisposed ABC-treated animals to develop skin hypersensitivity (data not shown). Taken together, these results indicated that the $\mathrm{ABC}$-induced adverse immune response in vivo was controlled by immunosuppressive mechanisms. This resulted from a systemic induction of reactive CD8 ${ }^{+}$ $\mathrm{T}$ cells that first entered an early activation phase, which was then arrested before progressing to tissue damage. The failure of PD-1 neutralization to predispose drug-treated $\mathrm{Tg}$ mice to develop ADR and the lack of coexpression of PD-1 with other inhibitory molecules on $\mathrm{ABC}$-responsive $\mathrm{CD} 8^{+} \mathrm{T}$ cells suggested that this control was exerted by cell-extrinsic mechanisms provided by immunosuppressive cells rather than cell-intrinsic mechanisms dependent on the expression of inhibitory receptors.

$C D 4^{+} T$ cell depletion predisposes $T g$ mice to $A B C$ reactivity in vivo. Patients at risk of developing AHR after exposure to $A B C$ are HLA-B ${ }^{*} 57: 01^{+}$HIV-infected individuals who may have an altered immune system shaped by a variety of factors including the virus. Given this and considering that HIV targets $\mathrm{CD} 4^{+} \mathrm{T}$ cells and that $\mathrm{ABC}$-reactive $\mathrm{CD} 8^{+} \mathrm{T}$ lymphocytes do not require $\mathrm{CD} 4^{+}$help to become activated, we explored whether CD4 depletion could alter the immune status of $\mathrm{Tg}$ animals, predisposing them to ADR.
Although human studies do not show a correlation between $\mathrm{CD} 4^{+}$ counts and susceptibility to developing AHR (16), the mouse model affords an opportunity to directly examine the potential role of CD4 depletion in $\mathrm{CD} 8^{+}$activation by $\mathrm{ABC}$. Therefore, we administered a depleting anti-mouse CD4 mAb (anti-CD4) to HLA-B ${ }^{*} 57: 01-\mathrm{Tg}$ mice periodically as outlined in Supplemental Figure 3B. Tg animals treated with $\mathrm{ABC}$ alone as well as $\mathrm{ABC}$-stimulated, $\mathrm{CD}$ 4-depleted (anti-CD4 + ABC) WT mice were used as controls. By week 3, the Tg mice treated with anti-CD4 plus $\mathrm{ABC}$ (anti-CD4 plus ABC Tg mice) showed robust signs of skin hypersensitivity on the treated ears, unlike the animals that were not CD4 depleted (Figure 2, A and F). The skin reaction was characterized by scarring, abundant dermal and epidermal infiltration of $\mathrm{CD} 8^{+} \mathrm{T}$ cells by IHC, and increased ear thickness (Figure 2, F and G, and Supplemental Figure 4). We did not observed skin hypersensitivity in anti-CD4 plus ABC WT mice and observed minimal skin hypersensitivity in the $\mathrm{Tg}$ animals that received anti-CD4 and vehicle instead of the drug (anti-CD4 + vehicle). We also found that by day 10 , the LNs of anti-CD4 plus $\mathrm{ABC} \mathrm{Tg}$ mice had a higher percentage of $\mathrm{CD} 8^{+} \mathrm{PD}-1^{+} \mathrm{T}$ cells than did the $\mathrm{ABC}$ or anti-CD4 plus vehicle $\mathrm{Tg}$ animals (Figure $2 \mathrm{H}$ ), suggesting an ongoing systemic reaction. These data implicated $\mathrm{CD} 4^{+}$ $\mathrm{T}$ lymphocytes in the maintenance of immune tolerance during treatment of the Tg mice with $\mathrm{ABC}$ and in the prevention of $\mathrm{ADRs}$, despite the presence of the genetic risk factor HLA-B ${ }^{\star} 57: 01$.

$C D 4$ depletion promotes the development of $A B C$-reactive $C D 8^{+}$ $T$ cells with an effector-like, skin-homing phenotype. Both control and CD4-depleted HLA-B*57:01-Tg mice responded to ABC with a marked accumulation of reactive CD8 $8^{+} \mathrm{PD}-1^{+} \mathrm{T}$ cells in the LNs. Expression of PD-1, a marker of both effector and dysfunctional T lymphocytes $(23,24)$, was insufficient to explain the apparent differences in the activation status of $\mathrm{ABC}$-responsive $\mathrm{CD}^{+} \mathrm{T}$ cells and the clinical outcome of $\mathrm{Tg}$ animals in each treatment arm. 
A

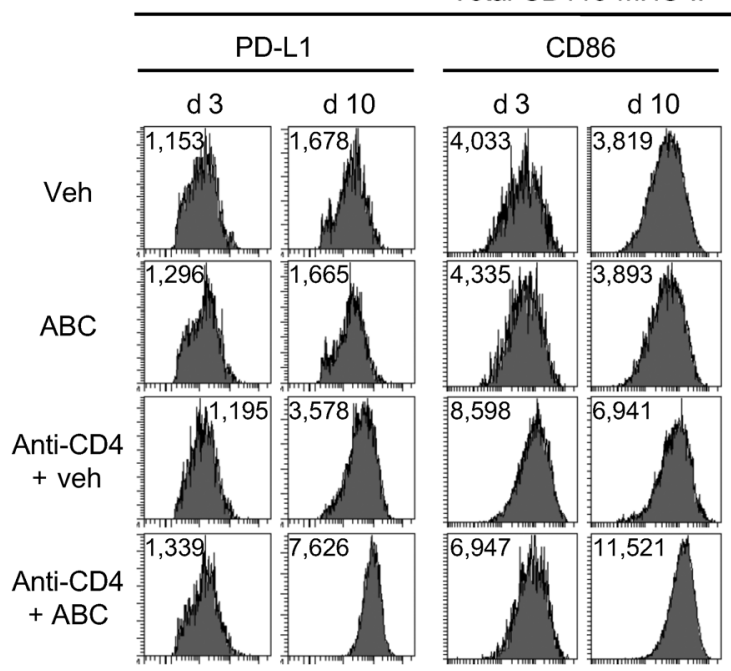

B

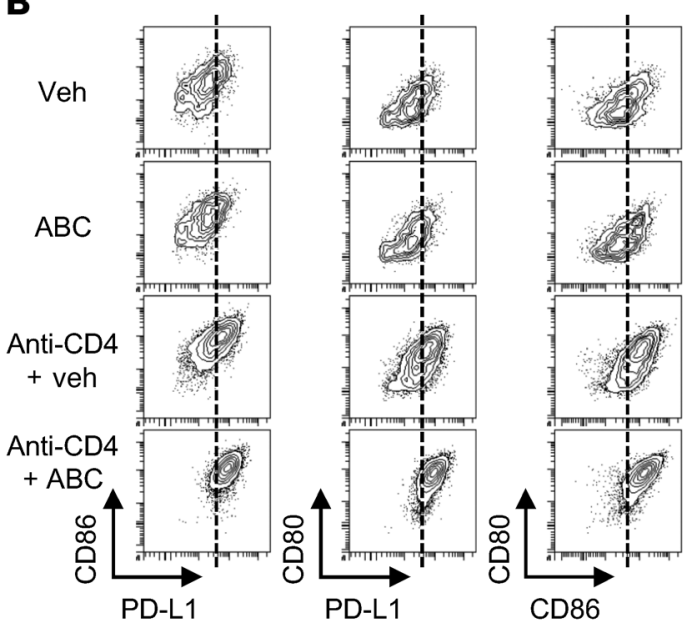

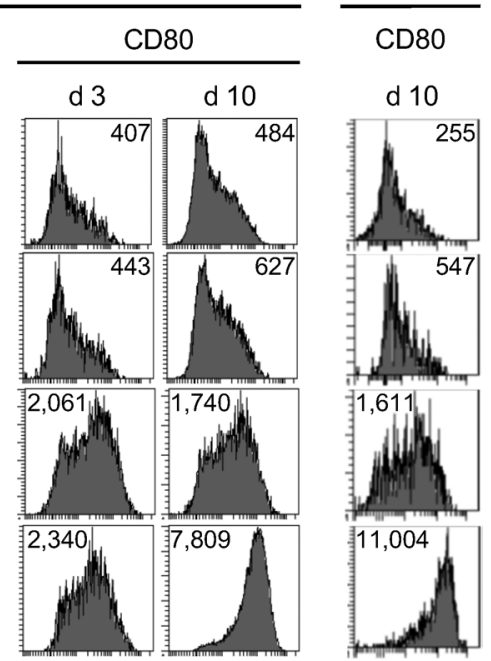

Figure 6. CD4 depletion leads to DC maturation, which is further enhanced by ABC treatment in Tg mice. (A) Median fluorescence intensity of maturation markers on total CD11 $\mathrm{C}^{+} \mathrm{MHC}-\mathrm{II}^{+} \mathrm{DCs}$ and $X C R 1^{+}$DC subsets in LNs of Tg mice at the indicated time of treatment. (B) Coexpression of PD-L1, CD86, and CD80 on total DCs from LNs on day 10 of treatment. Data are representative of at least 2 independent experiments. as well as Jak3, Lag3, and $\mathrm{Cd} 4 \mathrm{Olg}$ (Supplemental Figure 6), but also: (a) transcription factors including the immunosuppressive transcriptional regulator Egr3 (27, 33); (b) signaling molecules including the marker of T cell dysfunction $D g k z$ (34); and (c) cytokines and receptors (e.g., Lta, Tnf, Tnfsf8, Tnfrsflb, Tgfbr2) (Figure 3C and Supplemental Table 1). By day 10 , however, $\mathrm{ABC}-\mathrm{CD} 8^{+} \mathrm{T}$ cells showed traits of $\mathrm{CD}^{+} \mathrm{T}$ lymphocytes from vehicle-treated $\mathrm{Tg}$ mice (vehicle-CD8 ${ }^{+} \mathrm{T}$ cells) (Figure $3 \mathrm{~A}$ ), thus confirming the transient activation of drug-reactive $\mathrm{T}$ cells in immunocompetent $\mathrm{Tg}$ mice and suggesting a possible cause for the lack of development of ADR.

$\mathrm{CD} 8^{+} \mathrm{T}$ cells from anti-CD4 plus $\mathrm{ABC}$ Tg mice (anti-CD $4+\mathrm{ABC}-\mathrm{CD} 8^{+}$ $\mathrm{T}$ cells) showed a transcriptional phenotype markedly distinct from that

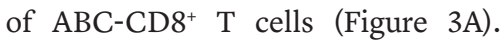
Although both types of cells shared expression of several genes related to $\mathrm{T}$ cell anergy, the transcriptional profile of anti-CD4 plus ABC-CD ${ }^{+}$T cells was particularly enriched for genes that define signatures of effector and exhausted $\mathrm{CD}^{+} \mathrm{T}$ cells in models of acute and chronic viral infections $(28,30$, and 31) (Figure 3B, and Supplemental Figure 6). Genes unique to the effector signature included Gzma,

Thus, to characterize better $\mathrm{ABC}$-reactive cells, we performed a comparative gene expression analysis of sorted $\mathrm{CD} 3^{+} \mathrm{CD} 4{ }^{-} \mathrm{CD} 8^{+} \mathrm{T}$ lymphocytes from LNs of nondepleted or CD4-depleted Tg mice treated with the drug. We focused on days 3 and 4 of $A B C$ exposure to identify the transcriptional phenotype of early activated $\mathrm{CD} 8^{+}$ $\mathrm{T}$ cells and on day 10 to reveal the characteristics of persistent drug-reactive $\mathrm{CD} 8^{+} \mathrm{T}$ lymphocytes in anti-CD4 plus $\mathrm{ABC} \mathrm{Tg}$ mice that eventually developed skin hypersensitivity. We evaluated the expression of 591 genes related to immune function, lymphocyte dysfunction, and/or effector responses, and we compared the resulting gene expression profiles with previously described gene signatures to identify associations with T cell anergy (27), exhaustion $(28,29)$, or effector function $(28,30,31)$, if any.

The gene expression profile of $\mathrm{CD}^{+} \mathrm{T}$ cells from $\mathrm{ABC} \mathrm{Tg}$ mice (ABC-CD $8^{+} \mathrm{T}$ cells) on day 3 showed a significant $(P=$ 0.0478 ) increase only in $P d c d 1$ (encoding PD-1). ABC-CD8 ${ }^{+} \mathrm{T}$ cells, however, further differentiated by day 4 and acquired a distinct gene signature enriched with genes associated with the anergic signature of $\mathrm{T}$ cells stimulated in the absence of costimulation, as described by Safford et al. (27) (Figure 3, A and B, and Supplemental Table 1). Core genes of this signature were $\mathrm{Natc1}$, a transcriptional regulator of the inhibitory receptor PD-1 (32),
Ccr2, Il12rb2, Il18r1, Il18rap, Klrc1, Casp1, Itgax, and Itgb1, whereas those associated with both effector and exhaustion signatures included the inhibitory receptors $P d c d 1, L a g 3$, and Ctla 4 as well as several chemokines and chemokine receptors (Figure 3D, Supplemental Figure 6, and Supplemental Table 2). Genes that were progressively upregulated from day 3 to day 10 in anti-CD4 plus ABC$\mathrm{CD} 8^{+} \mathrm{T}$ cells were: (a) transcriptional regulators (e.g., Ikzf4, Rorc) including the master transcription factor Tbx21; (b) inflammatory chemokines (e.g., Ccl4, Cxcl10); (c) cytokines and receptors (e.g., $I l 21, I l 2 r b$, Il12rb1); (d) the apoptosis-inducing molecule Fasl; and (e) activation and inhibitory markers (Cd44, Icos, Havcr2, Lilrb4, Tigit). These data highlight the coexistence of $\mathrm{CD} 8^{+} \mathrm{T}$ cell subsets with different states of activation within the LNs of anti-CD4 plus $\mathrm{ABC}$ Tg animals. Traits of $\mathrm{T}$ cell exhaustion within this population most likely reflect: (a) the progression of the drug-induced adverse immune response generated in the absence of $\mathrm{CD}^{+} \mathrm{T}$ cells toward a late state of activation, and/or (b) the effect of CD4 depletion, since exhaustion genes were predominantly expressed in $\mathrm{CD} 8^{+}$ $\mathrm{T}$ cells from anti-CD4 plus vehicle Tg mice (anti-CD4 + vehicle$\mathrm{CD} 8^{+} \mathrm{T}$ cells) (Figure 3, Supplemental Figure 6, and Supplemental Table 3). Moreover, the distinct gene signature in anti-CD4 plus $\mathrm{ABC}-\mathrm{CD} 8^{+} \mathrm{T}$ cells underscored the effector and cytotoxic 
A

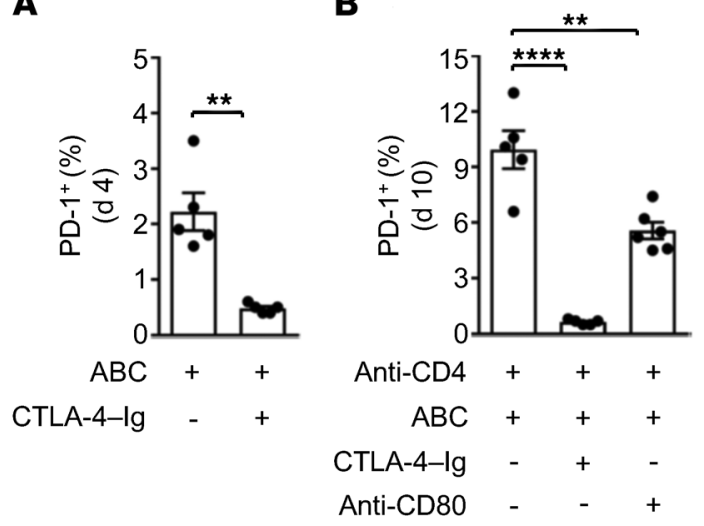

C

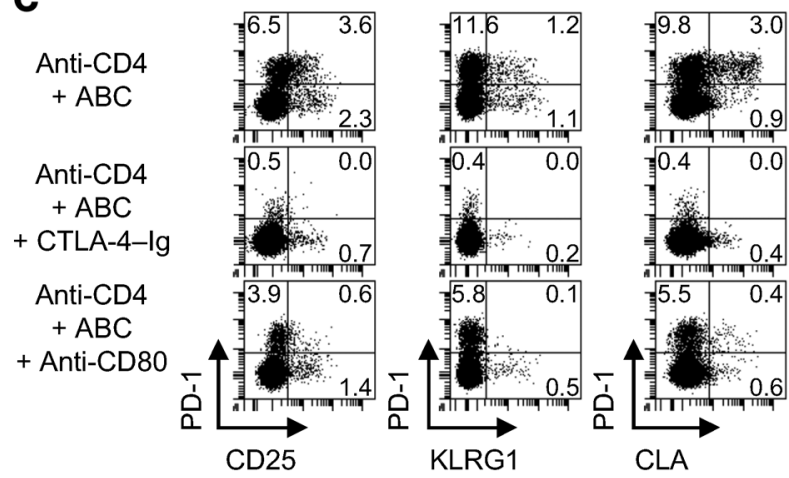

Figure 7. ABC-reactive $\mathrm{CD8}{ }^{+} \mathrm{T}$ cell differentiation is compromised by inhibition of costimulation in vivo. Flow cytometric analysis of $L N$ cells from $\mathrm{Tg}$ animals treated as indicated. (A and $\mathbf{B}$ ) Percentage of PD-1+ cells within $\mathrm{CD}^{+} \mathrm{T}$ lymphocytes at the indicated time point of treatment. Dots indicate values for individual mice ( $n=5-6$ per group). Three of five animals in the $A B C$ control group in $\mathbf{A}$ were also included in the day $4 A B C$-treated group in Figure $2 \mathrm{~B}$, while three of five mice in the anti-CD4 plus $\mathrm{ABC}$-treated control group in $B$ were also included in the anti-CD4 plus $A B C$ treatment group in Figure $2 \mathrm{H}$. (C) Percentage of $\mathrm{PD}-1^{+}, \mathrm{CD}_{2} 5^{+}, \mathrm{KLRC}^{+}$, and $\mathrm{CLA}{ }^{+}$cells within CD8 ${ }^{+} \mathrm{T}$ lymphocytes at day 10 of drug administration. Data are from 1 of 2 representative experiments. Data represent the mean \pm SEM. ${ }^{* *} P<0.005$ and ${ }^{* * *} P<0.0001$, by unpaired, 2-tailed Student's $t$ test (A) or 1-way ANOVA with Tukey's multiple comparisons correction (B).

potential of these cells to cause the in vivo outcome observed in mice of this group.

We next performed flow cytometric analysis on cells from LN, spleen, and blood to confirm the protein expression levels of several of the genes identified in the transcriptional signatures and/or to examine the state of activation of the $\mathrm{CD} 8^{+} \mathrm{T}$ cells later during disease. By day 10 of drug administration, $\mathrm{CD}^{+} \mathrm{T}$ lymphocytes in the LNs of only the anti-CD4 plus ABC Tg animals were highly enriched for cells coexpressing the inhibitory receptors PD-1 and LAG3 and TIM3 or CTLA-4 (likely representing T cells in an advanced state of activation or exhaustion), as well as for subpopulations of T cells expressing only CD25, KLRG1, and/ or PD-1 (possibly representing $\mathrm{T}$ cells in a more active functional state) (Figure 4, A and B). CD25 $5^{+}$and/or KLRG1 ${ }^{+} \mathrm{CD} 8^{+} \mathrm{T}$ cells were found in LNs, spleen, and blood of anti-CD4 plus ABC Tg mice, even at 3 week of drug exposure (Figure $4 \mathrm{C}$ ), when animals manifested skin hypersensitivity on the treated ears. At the same time, a significant proportion of splenic anti-CD4 plus ABC-
$\mathrm{CD}^{+} \mathrm{T}$ cells also expressed the costimulatory receptor 4-1BB (Figure 4D) as well as Ifng and Gzmb (data not shown) when restimulated in vitro with drug, unlike cells from animals of the other treatment groups. In addition, LNs and blood from anti$\mathrm{CD} 4$ plus $\mathrm{ABC} \mathrm{Tg}$, but not WT, mice revealed an increased percentage of $\mathrm{CD} 8^{+} \mathrm{T}$ cells expressing the skin-homing molecules CLA and CXCR3 (Figure 5A). These results indicate that in anti$\mathrm{CD} 4$ plus $\mathrm{ABC}$ Tg animals, activated $\mathrm{ABC}$-responsive $\mathrm{CD} 8^{+} \mathrm{T}$ lymphocytes have the potential to target the skin, despite showing some dysfunctional traits, and can still be detected in the circulation by week 3 of treatment. Consistently, by week 3 , skin biopsies from anti-CD4 plus ABC Tg animals showed remarkable inflammation characterized by infiltrating effector $\mathrm{CD} 8^{+} \mathrm{T}$ cells (Figure 2F and Supplemental Figure 4) and macrophages (data not shown) and elevated expression of genes encoding effector markers, cytotoxic factors, inflammatory chemokines, and adhesion molecules (Figure 5B). Thus, CD4 depletion, although promoting $\mathrm{T}$ cell dysfunction when administered alone, conditioned the immune system of $\mathrm{Tg}$ mice toward becoming more permissive for $\mathrm{ABC}$ to induce ADRs.

$C D 4$ depletion boosts the $D C$ maturation required for induction of skin-homing, $A B C$-reactive $C D 8^{+} T$ cells in vivo. Enrichment in anti-CD4 plus $\mathrm{ABC}-\mathrm{CD} 8^{+} \mathrm{T}$ cells of gene sets characteristic of effector $\mathrm{T}$ cells from viral infection models in which costimulatory and inflammatory conditions were optimal led us to hypothesize possible mechanisms by which the lack of $\mathrm{CD}^{+} \mathrm{T}$ cells could overcome tolerance. $\mathrm{CD} 4^{+}$Tregs can control autoimmunity as well as graft-versus-host disease by restraining DC maturation (35-38). Therefore, we explored whether a similar mechanism of action could be in place in our model by characterizing the maturation profile of DCs from the treated Tg mice. We analyzed the expression of the costimulatory molecules CD86, CD80, and CD40, the coinhibitory receptor PD-L1, and HLA-B ${ }^{*} 57: 01$ on total CD11 $\mathrm{c}^{+} \mathrm{MHC}-\mathrm{II}{ }^{+} \mathrm{DC}$ and the subset of XCR1 ${ }^{+}$DCs from LNs (Figure 6A and Supplemental Figure 7, A and B). We found that the levels of expression of these molecules were similar on DCs from $\mathrm{ABC}$ - and vehicle-treated $\mathrm{Tg}$ animals and did not change during the first 10 days of exposure to the drug. Regardless of $\mathrm{ABC}$ treatment, DCs from CD4-depleted Tg mice had increased expression of CD86 and, more markedly, CD80, but not PD-L1, CD40, or HLA-B ${ }^{*} 57: 01$ at day 3 . By day 10 , however, the presence of drug enhanced the expression of all molecules compared with anti-CD4 treatment alone, except for CD40, which was likely due to the presence of activated $\mathrm{CD} 8^{+} \mathrm{T}$ lymphocytes. We observed a similar effect for the expression of CD80 and HLA-B ${ }^{*} 57: 01$ on the XCR1 ${ }^{+}$DC subpopulation (Figure $6 \mathrm{~A}$ and Supplemental Figure 7, A and B). Notably, DCs with higher levels of CD80 and CD86 expression, particularly those from anti-CD4 plus $\mathrm{ABC} \mathrm{Tg}$ animals, also showed greater expression of PD-L1 (Figure 6B). CD80 has been demonstrated by others to prevent the inhibitory interaction of PD-L1-PD-1 by binding to PD-L1, while also costimulating via CD28 on T lymphocytes (39-41). Similarly, the high levels of CD80 expression on DCs from anti-CD4 plus ABC Tg mice may lead to an effective costimulatory phenotype, overcoming the PD-L1-inhibitory effect.

To test the impact of costimulation on the development of drug-responsive $\mathrm{CD} 8^{+} \mathrm{T}$ cells in vivo, $\mathrm{ABC} \mathrm{Tg}$ animals and anti- 
A

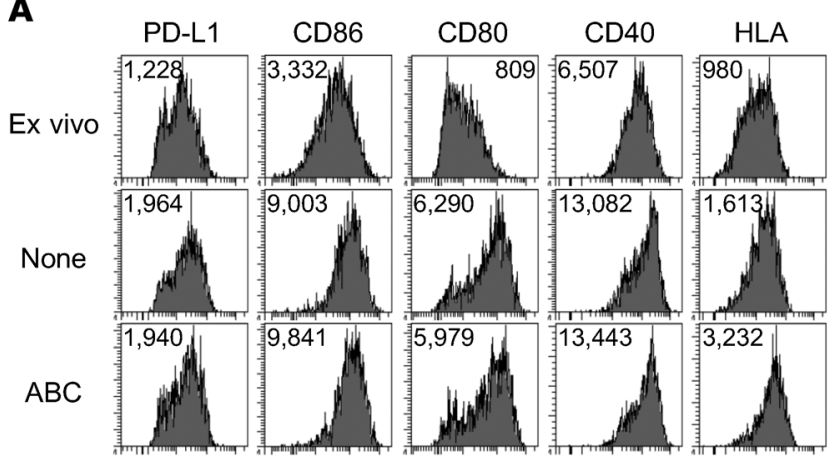

B

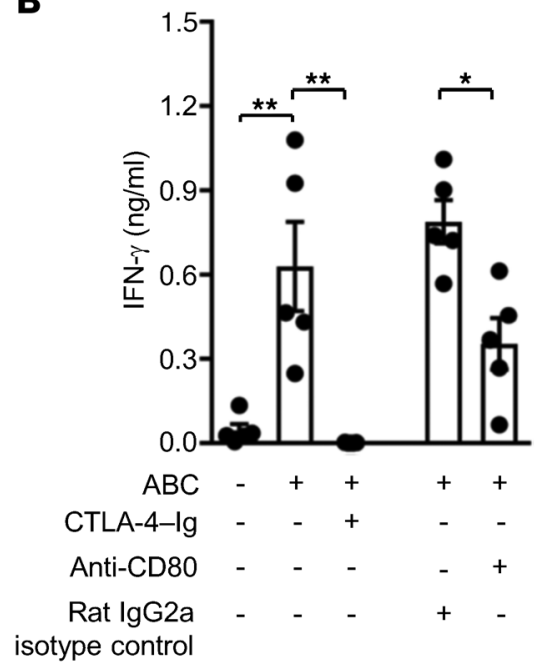

Figure 8. Costimulation with CD80 and CD86 supports activation of ABC-reactive Tg cells in vitro. (A) Median fluorescence intensity of maturation markers and HLA-B*57:01 on CD11 ${ }^{+}$MHC-II+ DCs of LN cells from drug-naive Tg mice. Measurements were done ex vivo and after overnight culture in the absence or presence of $A B C$. Data are from 1 of 2 representative experiments. (B) IFN- $\gamma$ in supernatants from day- $5 \mathrm{LN}$ cell cultures of drug-naive Tg mice. Cells were treated with $A B C$ in the absence (none) or presence of CTLA-4-Ig, anti-CD80 mAb, or rat IgG2a isotype control. Data represent the mean \pm SEM of ELISA results. Dots indicate values for individual mice ( $n=5$ per group). ${ }^{*} P<0.05$ and ${ }^{* *} P<0.005$, by 1 -way ANOVA with Tukey's multiple comparisons correction.

CD4 plus ABC Tg mice were injected with CTLA-4-Ig to block CD80 and CD86, or with anti-CD80-neutralizing mAb. Treatment with CTLA-4-Ig inhibited the accumulation of reactive $\mathrm{CD} 8{ }^{+} \mathrm{PD}-1^{+} \mathrm{T}$ lymphocytes in the LNs of ABC Tg mice, seen on day 4 (Figure 7A), indicating that basal levels of CD80 and CD86 were required for the transient activation of $\mathrm{ABC}$-responsive $\mathrm{CD} 8^{+} \mathrm{T}$ cells observed in immunocompetent animals. We observed a similar effect in anti-CD4 plus ABC Tg mice (Figure 7B), with complete inhibition of $\mathrm{T}$ cell activation by day 10. Anti-CD80 $\mathrm{mAb}$ treatment in anti-CD4 plus ABC Tg animals partially inhibited the accumulation of reactive $\mathrm{PD}-1^{+} \mathrm{T}$ lymphocytes, but markedly reduced the expression of CD25, KLRG1, and CLA on CD8 ${ }^{+} \mathrm{T}$ cells (Figure 7, B and C). These results indicated that optimal costimulation was likely necessary for the differentiation of functionally active, skin-homing, $\mathrm{ABC}$-responsive $\mathrm{CD}^{+} \mathrm{T}$ cells in anti-CD4 plus ABC Tg mice.

The requirement of CD4 depletion to activate drug-reactive $\mathrm{CD}^{+} \mathrm{T}$ cells in vivo, however, appeared to conflict with the activation of $\mathrm{CD}^{+} \mathrm{T}$ lymphocytes by $\mathrm{ABC}$ in vitro, which occurred regardless of the presence of $\mathrm{CD}^{+} \mathrm{T}$ cells. To address this, we explored the level of DC maturation in LN cells from drug-naive mice ex vivo and in culture. Surprisingly, DC maturation, characterized by upregulation of the B7 costimulatory molecules CD86 and CD80, occurred as a consequence of cell culture, even in the absence of ABC (Figure 8A and Supplemental Figure 8). Addition of CTLA-4-Ig or anti-CD80 mAb to cultures impaired the production of IFN- $\gamma$ by LN cells treated with ABC (Figure 8B).

Taken together, these results indicated that APC-dependent costimulation was needed for $\mathrm{ABC}$ to activate $\mathrm{CD}^{+} \mathrm{T}$ lymphocytes. In vivo, unlike in vitro, DC maturation was boosted by the lack of $\mathrm{CD}^{+} \mathrm{T}$ cells, which was required to develop drugreactive effector $C D 8^{+} \mathrm{T}$ cells with pathogenic potential in this mouse model of HLA-B ${ }^{\star} 57$ :01-linked ABC drug reactivity.

\section{Discussion}

The discovery of genetic associations between certain ADR and HLA alleles led to the examination of immune mechanisms underlying the manifestation of HLA-restricted drug-allergies. These efforts resulted in several studies that shed light on models of HLA-drug-peptide-TCR interaction and on the nature of drug-reactive T cell responses $(1,42)$. Of note, earlier studies were performed in vitro and failed to explain why some patients carrying a known HLA risk allele tolerate the culprit drug, highlighting the complexity of the immunopathogenesis of HLA-linked ADRs in the living organism $(13,16,17)$. Here, we used an HLA-B ${ }^{\star} 57: 01-$ $\mathrm{Tg}$ mouse and reveal: (a) the nature of the systemic but defective response to $\mathrm{ABC}$ in drug-tolerant $\mathrm{Tg}$ animals, which may explain ABC tolerance in $45 \%$ of HIV-infected HLA-B ${ }^{*} 57: 01^{+}$individuals, and (b) the need for optimal costimulation for $\mathrm{ABC}$ to induce drug-reactive effector $\mathrm{CD}^{+} \mathrm{T}$ cells with potential to cause skin hypersensitivity in $\mathrm{Tg}$ mice.

Using an approach similar to that described by others in human studies using cultures of peripheral blood mononuclear cells (PBMCs) from ABC-naive, HLA-B ${ }^{\star} 57: 01^{+}$healthy, normal donors $(10,11,13,14)$, we demonstrated here that splenic and $\mathrm{LN}$ cells from ABC-naive HLA-B ${ }^{\star} 57: 01-\mathrm{Tg}$ mice gave rise to functionally active, drug-responsive $\mathrm{CD} 8^{+}$, but not $\mathrm{CD} 4^{+}, \mathrm{T}$ cells when cultured in vitro with the drug. Consistent with the findings in humans, in vitro stimulation of mouse $\mathrm{CD} 8^{+} \mathrm{T}$ cells by $A B C$ required expression of the risk allele HLA-B ${ }^{\star} 57: 01$. However, compared with the response observed in PBMCs from $\mathrm{ABC}$ naive, HLA-B ${ }^{\star} 57: 01^{+}$healthy, normal donors, $\mathrm{Tg} \mathrm{CD}^{+} \mathrm{T}$ cells in our study reacted more rapidly to $\mathrm{ABC}$ and became activated within 5 days of stimulation with the drug.

We next tested the effects of $A B C$ exposure in vivo, expecting that a fraction of the HLA-B ${ }^{\star} 57: 01-\mathrm{Tg}$ mice would develop adverse reactions after drug administration, given the studies in 
humans $(16,17)$. However, unlike HIV-infected patients, Tg animals tolerated ABC without showing signs of AHR. Nevertheless, we noticed an accumulation of drug-reactive $\mathrm{CD} 8^{+} \mathrm{T}$ cells expressing PD-1 in the LNs of the treated mice. These lymphocytes originated predominantly from $\mathrm{CD} 44^{\mathrm{hi}} \mathrm{CD} 62 \mathrm{~L}^{\text {hi }}$ memory-like cells, suggesting that even in $\mathrm{Tg}$ animals, preexisting memory $\mathrm{CD}^{+}$ $\mathrm{T}$ cells, directed against either self or foreign antigens, could be a source of drug-responsive $\mathrm{T}$ lymphocytes, as was similarly proposed in humans $(13,14)$. Of note, "innate" memory T cells recognizing self-peptide-MHC ligands exist even in germ-free animals and in mice housed under pathogen-free conditions (43). Further studies on memory cells identified in our model will be required to further characterize the $\mathrm{ABC}$-specific response.

In vivo, reactive $\mathrm{PD}-1^{+} \mathrm{T}$ cells proliferated and lost the naive/ memory marker CD62L within 4 days of treatment, showing their potential to enter an early activation phase. However, PD-1 $1^{+}$ $\mathrm{T}$ cells were only transiently detectable and returned to basal levels by day 10 . These $\mathrm{ABC}-\mathrm{CD} 8^{+} \mathrm{T}$ cells shared anergic traits previously associated with $\mathrm{T}$ cells stimulated in the absence of costimulation (27). Of note was the expression of the zinc finger transcription factor gene Egr3, which, together with Egr2, has been shown to prevent autoimmunity (44) by driving a negative genetic program responsible for dampening effector differentiation and promoting $\mathrm{T}$ cell anergy $(27,33)$, while ensuring a certain level of proliferation (33). ABC-CD8 ${ }^{+} \mathrm{T}$ cells also expressed PD-1 and its transcriptional regulator $N$ fatc1 (32). PD-1, which is rapidly upregulated upon activation, may be expressed on functionally active memory $\mathrm{T}$ lymphocytes (45), short-lived effectors, and especially on dysfunctional T cells (24) including anergic ones $(46,47)$. In the latter, PD-1 upregulation has been shown to promote anergy during tolerogenic stimulation in LNs (46), an action that could be mediated by suppressing IL-2 production of reactive $\mathrm{T}$ cells (47). In addition, interference with PD-1-PD-L1 interaction was proven to reverse this process (46). Thus, we explored whether blockade of PD-1 could prevent ABC$\mathrm{CD}^{+} \mathrm{T}$ cell dysfunction in the LNs of treated $\mathrm{Tg}$ mice, making them susceptible to develop drug reactivity. However, anti-PD-1 neither helped $\mathrm{ABC}-\mathrm{CD}^{+} \mathrm{T}$ cells to progress toward a functionally active state with skin-homing potential, nor predisposed ABC-treated $\mathrm{Tg}$ mice to develop ADRs. Overall, these results provided a model for $\mathrm{ABC}$ tolerance and highlight the finding that the exposure to a broad range of neoantigens caused by $\mathrm{ABC}$ treatment is not sufficient to induce AHR, despite the presence of the HLA genetic risk.

CD4 ${ }^{+}$Tregs have been shown to maintain immunological tolerance (48) and ensure memory $\mathrm{CD}^{+} \mathrm{T}$ cell quiescence under homeostatic conditions (49), a process that could also affect $\mathrm{ABC}$-responsive, preexisting memory $\mathrm{T}$ lymphocytes in $\mathrm{Tg}$ mice. In addition, as seen in human studies, we show here that $\mathrm{ABC}$ reactive $\mathrm{Tg} \mathrm{CD} 8^{+} \mathrm{T}$ cells do not require $\mathrm{CD} 4^{+}$help to become activated. Therefore, we depleted $\mathrm{CD}^{+} \mathrm{T}$ cells prior to $\mathrm{ABC}$ administration to explore whether this immune alteration could predispose HLA-B ${ }^{\star 57: 01-T g ~ m i c e ~ t o ~ d e v e l o p ~ A D R s . ~ S i m i l a r ~ t o ~ w h a t ~}$ was observed in AHR patients (7), skin from the treated ears of anti-CD4 plus ABC Tg animals showed signs of cutaneous reaction characterized by remarkable inflammation and the presence of infiltrating cytotoxic $\mathrm{CD}^{+} \mathrm{T}$ cells. The skin was also infiltrated by macrophages that were possibly recruited by locally produced chemokines such as CCL5. The anti-CD4 plus ABC treatment, however, did not allow the assessment of skin infiltration by $\mathrm{CD}^{+}$ $\mathrm{T}$ cells, as seen in skin biopsies from ABC-hypersensitive patients (7), because of the depletion of these cells. Although systemic $\mathrm{CD}^{+} \mathrm{T}$ cell activation occurred in LNs, spleen, and blood, other clinical symptoms related to AHR observed in $\mathrm{HIV}^{+}$individuals (6), such as increased body temperature (data not shown) or lethargy, were not observed. Thus, anti-CD4 plus ABC Tg mice cannot be considered an exact model for human AHR, but rather a model for generating HLA-B ${ }^{\star} 57$ :01-linked ABC-reactive $C D 8^{+} \mathrm{T}$ cells with pathogenic potential. Indeed, though mouse models are critical for the objective evaluation of both genetic and environmental factors in terms of their contribution to disease etiology, many aspects of human biology cannot be accurately assessed in such models. Data from multiple study approaches - animal and human, in vivo and in vitro, experimental and observational - must be integrated to develop an accurate mechanistic understanding.

Unlike $\mathrm{ABC}-\mathrm{CD}^{+} \mathrm{T}$ cells, $\mathrm{CD}^{+}{ }^{+} \mathrm{T}$ lymphocytes from anti$\mathrm{CD} 4$ plus $\mathrm{ABC}$ Tg mice displayed gene expression patterns similar to those reported for effector $T$ cells in acute viral infection models $(28,30,31)$, in which adaptive immune responses arise under optimal costimulatory conditions. Nevertheless, anti-CD4 plus ABC$\mathrm{CD}^{+} \mathrm{T}$ cells also showed molecular traits found in dysfunctional lymphocytes (27-29), particularly in exhausted cells, indicating the coexistence of reactive $\mathrm{CD}^{+} \mathrm{T}$ cells at different activation states in Tg mice treated with anti-CD4 and ABC. Since anti-CD4 plus vehicle-CD ${ }^{+} \mathrm{T}$ cells showed predominantly markers of dysfunction, we thus concluded that the presence of dysfunctional $\mathrm{CD}^{+} \mathrm{T}$ cells in anti-CD4 plus ABC Tg animals was mainly due to the effect of CD4 depletion, as has been described in infection and vaccination models $(23,50)$. Moreover, selective depletion and/or impaired functionality of Tregs have been shown to lead to autoimmunity $(37,51,52)$. Instead, in our $\mathrm{Tg}$ mice, the loss of $\mathrm{CD} 4^{+} \mathrm{T}$ cells alone, which included CD4 ${ }^{+}$Tregs, had mild effects, and the presence of $\mathrm{ABC}$ was necessary for the development of pathogenic drug-reactive $\mathrm{CD} 8^{+} \mathrm{T}$ cells and skin hypersensitivity.

The strikingly different gene expression phenotypes of ABC$\mathrm{CD}^{+}$and anti-CD4 plus $\mathrm{ABC}-\mathrm{CD} 8^{+} \mathrm{T}$ cells along with the wellknown role of CD4+ Tregs in preventing DC maturation (35-38, 53, 54) made us question whether loss of $\mathrm{CD} 4^{+} \mathrm{T}$ lymphocytes overcame the immune tolerance to $\mathrm{ABC}$ and predisposed HLA-B ${ }^{*} 57: 01-\mathrm{Tg}$ mice to develop $\mathrm{ABC}$ drug reactivity by enhancing $\mathrm{DC}$ maturation. Indeed, we found that treatment with anti-CD4 mAb alone, and even more so in the presence of the drug, upregulated the expression of costimulatory molecules on total lymphoid CD11c ${ }^{+} \mathrm{MHC}-\mathrm{II}^{+} \mathrm{DCs}$ that were required in $\mathrm{Tg}$ animals exposed to $\mathrm{ABC}$ for the differentiation of drug-reactive $\mathrm{CD}^{+} \mathrm{T}$ cells with potential to target the skin.

During viral infection, $\mathrm{CD} 4^{+} \mathrm{T}$ lymphocytes have been shown to provide help priming $\mathrm{CD} 8^{+} \mathrm{T}$ cells when colocalized with them on XCR1 $1^{+}$DCs in LNs $(55,56)$. However, several reports $(13,14)$ demonstrated that $\mathrm{CD}^{+} \mathrm{T}$ cell help is not required for expanding $\mathrm{ABC}$-reactive $\mathrm{CD} 8^{+} \mathrm{T}$ lymphocytes in cultures of memory or naive cells from HLA-B*57:01+ donors, and our results with Tg mice supported this finding. We also found that in vivo $\mathrm{CD} 4^{+} \mathrm{T}$ cells can prevent adverse immune responses to $\mathrm{ABC}$ by keeping the state of DC activation under control. Therefore, we hypothesize that in 
$\mathrm{ABC} \mathrm{Tg}$ animals, $\mathrm{XCR}^{+} \mathrm{DCs}$ can provide drug-responsive $\mathrm{CD}^{+}$ T lymphocytes with tolerogenic stimulation when $\mathrm{CD} 4^{+}$Tregs are present in the co-cluster or allow an optimal costimulation when Tregs are absent. Indeed, we observed a remarkable increase in expression of CD80 and HLA-B ${ }^{\star} 57: 01$ molecules on XCR1 ${ }^{+}$DCs in the LNs of $\mathrm{ABC}$ Tg mice after $\mathrm{CD} 4^{+} \mathrm{T}$ cell depletion. This suggested that $\mathrm{XCR} 1^{+}$DCs could help determine the fate of drugresponsive $\mathrm{CD}^{+} \mathrm{T}$ cells in vivo and, eventually, the outcome of the response to $\mathrm{ABC}$ - tolerogenic or adverse - depending on the presence or absence of CD $4^{+}$Tregs in the immediate vicinity. Additional experiments are needed to definitively address the role of Tregs and $\mathrm{CD} 4^{+} \mathrm{T}$ cells.

Our study highlights the importance of DC-mediated costimulation in influencing the outcome of the response to ABC. Costimulation by professional APCs has been widely recognized as an essential process in providing signal 2 in addition to TCR binding for the activation of both naive and memory T cells (57). However, Adam et al. (13) reported that the intervention of the innate immune system, in particular of professional APCs, is not necessary to trigger $\mathrm{T}$ cell responses to $\mathrm{ABC}$ in vitro. This conclusion was drawn on the basis of results showing that: (a) ABC does not directly activate in vitro-generated DCs from HLA-B ${ }^{\star} 57: 01^{+}$individuals to upregulate costimulatory molecules or release inflammatory cytokines (IL-1 $\beta$, IL-6, TNF); and (b) ABC reactivity can be detected after drug rechallenge in cultures of pure HLA-B ${ }^{\star 57: 01^{+}}$ $\mathrm{T}$ cells that were previously expanded in the absence of APCs. Consistent with these reports, we show here that even in Tg mice, $\mathrm{ABC}$ alone does not directly activate $\mathrm{DCs}$, either in vivo or in overnight cultures of LN cells. However, beyond the effects of $\mathrm{ABC}$ on DC activation and as previously reported by others $(58,59)$, we also found that DCs from Tg mice spontaneously matured in vitro, regardless of the presence of the drug, and upregulated B7 costimulatory molecules that support the in vitro differentiation of functionally active $\mathrm{ABC}$-responsive $\mathrm{CD} 8^{+} \mathrm{T}$ cells, as shown in vivo. Thus, our findings, along with a recent report (60) demonstrating that ABC activates the NLRP3 inflammasome for IL-1 $\beta$ release in pathogen-associated molecular pattern-primed (PAMP-primed) human monocytes, reinforce the potential role of the innate immune system, particularly of APCs, in contributing to ABC drug reactivity. Furthermore, the different requirements for DC maturation in vivo and in vitro, as evidenced by our study, might explain differences in the frequency of $\mathrm{ABC}$-induced immune responses in patients in vivo and in culture.

A role of $\mathrm{CD} 4^{+}$Tregs, costimulatory molecules, and/or coinhibitory receptors in the context of drug allergies has been previously suggested in: (a) a mouse model of dinitrofluorobenzene-induced (DNFB-induced) contact hypersensitivity (61); (b) CD4-deficient mice treated with flucloxacillin to model DILI (62); and (c) human cell cultures exposed to flucloxacillin or nitroso sulfamethoxazole (SMX-NO) $(63,64)$. Our study explores the effects of the above-mentioned immunoregulatory players in the context of $\mathrm{ABC}$ drug reactivity, especially in vivo, and using a Tg mouse carrying the associated risk allele HLA-B ${ }^{*} 57: 01$.

Of note, the complete depletion of $\mathrm{CD}^{+} \mathrm{T}$ cells achieved in our $\mathrm{Tg}$ model for $\mathrm{ABC}$ drug reactivity is more pronounced than that seen in HIV patients in clinical practice. However, it is well accepted that gut-homing, HIV-specific CD $4^{+} \mathrm{T}$ cells are severely depleted in the intestinal mucosa and show only partial recovery under combination antiretroviral therapy (65). Since this alteration is also associated with microbial translocation (leaking gut), persistent inflammation, and innate and adaptive immune activation, it is possible that anti-CD4-treated Tg mice may also experience similar effects and therefore be more susceptible to $\mathrm{ABC}$ exposure, a hypothesis that needs further investigation.

Recently, Susukida et al. (66) reported T cell responses to $\mathrm{ABC}$ in a HLA-B ${ }^{*} 57: 01-\mathrm{Tg}$ mouse that coexpressed human B2M, within 1 week of drug administration. Consistent with our results, the authors measured a rapid increase in $\mathrm{CD} 44^{\text {hi }} \mathrm{CD} 62 \mathrm{~L}^{\text {lo }} \mathrm{CD} 8^{+} \mathrm{T}$ cells in LNs and spleen in vivo when $\mathrm{ABC}$ was administered orally. Lymphocyte infiltration was observed in skin after ear painting with $\mathrm{ABC}$ for 3 days. In contrast, we noted that $\mathrm{ABC}$ administration did not directly lead to skin inflammation or scarring and that systemic activation of $\mathrm{CD} 8^{+} \mathrm{T}$ cells resulted in tolerance within 10 days of drug administration. Susukida et al. did not address the evolution of the early response to $\mathrm{ABC}$ in their model, nor did their animals show any clinical effects. Another recently published report from this group described transient alanine aminotransferase (ALT) elevation and liver inflammation 5 days after treatment of mice with CpG-ODN, a TLR-9 agonist, together with ABC (67). We did not observe liver inflammation by histology in our Tg mice, even when animals were depleted of $\mathrm{CD} 4^{+} \mathrm{T}$ cells and showed robust drug-induced activation of effector $\mathrm{CD} 8^{+} \mathrm{T}$ cells.

In conclusion, we exploited a $\mathrm{Tg}$ animal model for HLA-B ${ }^{\star}$ 57:01-linked ADR focused on ABC tolerance and the generation of drug-reactive $\mathrm{CD} 8^{+} \mathrm{T}$ cells with pathogenic potential. This HLA-B ${ }^{\star} 57: 01-\mathrm{Tg}$ mouse allows the simultaneous in vivo modeling of the susceptibility conferred by HLA genetic risk and immune regulatory factors that can mitigate pathology. Although AHR in patients may not correlate with CD4 counts (16), depletion of $\mathrm{CD}^{+}{ }^{+}$in $\mathrm{HLA}-\mathrm{B}^{*} 57: 01-\mathrm{Tg}$ mice revealed that optimal DC-mediated costimulation predisposed the mice to a break in immune tolerance in the presence of ABC. Nevertheless, since anti-CD4 plus ABC Tg animals did not manifest the full spectrum of clinical symptoms seen in AHR patients, other factors required for AHR development remain to be disclosed. In addition, since HLA-B ${ }^{\star} 57: 01$ is also associated with DILI caused by flucloxacillin or pazopanib, we expect that these $\mathrm{Tg}$ mice can help us to better understand the immunopathogenesis of these reactions. Given the unique ability of $\mathrm{ABC}$ to activate $\mathrm{CD}^{+} \mathrm{T}$ cells in the absence of $\mathrm{CD}^{+} \mathrm{T}$ cells, additional host factor variables may need to be explored to explain adverse reactions to other drugs. Finally, our work suggests that HLA $\mathrm{Tg}$ animals may be used for in-depth characterization of other HLA-linked ADRs.

\section{Methods}

Mice. The HLA-B ${ }^{*} 57: 01 / H 2-D^{d}$ full-length chimeric construct was generated from a full-length HLA-B ${ }^{*}$ 77:01 cDNA. The sequences encoding the HLA-B ${ }^{*} 57: 01 \alpha 1$ and $\alpha 2$ domains were joined to the $\alpha 3$, transmembrane (TM), and cytoplasmic (CY) domains from a cDNA of $\mathrm{H} 2-\mathrm{D}^{\mathrm{d}}$ and subcloned into the vector containing an $\mathrm{H} 2-\mathrm{K}^{\mathrm{b}}$ promoter, $3^{\prime}$ splice, and Ig enhancer designed for transgenic expression (68), as described in greater detail elsewhere (our unpublished observations). HLA-B ${ }^{\star 57: 01-}$ $\mathrm{Tg}$ mice were generated by microinjection of C57BL/6 embryos at the 
National Cancer Institute transgenic mouse facility using standard methods (69). Founders, identified by Southern blotting, were then followed by flow cytometry on peripheral blood leukocytes with $\mathrm{mAb}$ B1.23.2 (70). The animals used in these studies are designated $\mathrm{Ch} / \mathrm{L}-2$ (our unpublished observations) and are heterozygous for the transgene on the C57BL/ 6 background. The genotype of animals was verified by flow cytometry as detailed in the Methods section Flow cytometry, cell sorting, and in vivo proliferation assays. Tg and WT (male and female) experimental mice were above 8 weeks of age. All mice were bred and housed under specific pathogen-free conditions.

In vitro culture assays. In vitro $\mathrm{T}$ cell responses to $\mathrm{ABC}$ were measured in cultures of purified $\mathrm{CD} 8^{+} \mathrm{T}$ lymphocytes and single-cell suspensions from spleens or pooled LNs of WT and/or HLA-B ${ }^{*} 57: 01-T g$ mice. Enrichment of $\mathrm{ABC}$-reactive $\mathrm{CD} 8^{+} \mathrm{T}$ lymphocytes was achieved by adding 10 $\mu \mathrm{g} / \mathrm{ml} \mathrm{ABC}$ (Ziagen tablets, GlaxoSmithKline) to the cultures on day 0 . Purified $\mathrm{CD}^{+} \mathrm{T}$ lymphocytes were cocultured on day 0 with irradiated (30 Gy) splenocytes at a 1:2 $\mathrm{CD}^{+} \mathrm{T}$ cell to feeder ratio. For ELISpot experiments, $\mathrm{ABC}$-reactive $\mathrm{CD} 8^{+} \mathrm{T}$ cells were first generated by culturing purified $\mathrm{CD}^{+} \mathrm{T}$ lymphocytes and irradiated feeders with $5 \mu \mathrm{g} / \mathrm{ml}$ $\mathrm{ABC}$ for 5 days and subsequently expanded in the presence of rhIL2 for up to 14 days. IFN- $\gamma$ secretion was evaluated by culturing ABC-reactive $\mathrm{CD}^{+} \mathrm{T}$ cells with feeders at a 1:4 ratio. When indicated, $\mathrm{mAb}$ or CTLA-4Ig (ORENCIA [abatacept], Bristol-Myers Squibb) were added to cultures.

Treatment of mice. WT and/or HLA-B ${ }^{\star} 57: 01-\mathrm{Tg}$ mice were injected i.p., 5 days a week for up to 4 weeks, with $3 \mathrm{mg} \mathrm{ABC}$ solution prepared as indicated in the Supplemental Methods section In vitro culture assays. To facilitate the development of a cutaneous reaction, both ears were painted as indicated in Supplemental Figure 3 with a solution of $0.2 \mathrm{mg} / \mathrm{ear}$ of $\mathrm{ABC}$, for up to 4 weeks. To deplete $\mathrm{CD}^{+}{ }^{+} \mathrm{T}$ cells, the animals were injected i.p. with $0.25 \mathrm{mg}$ anti-CD4 $\mathrm{mAb}$ (clone GK1.5, BioXcell) (Supplemental Figure 3B). To block PD-1 in vivo, $0.2 \mathrm{mg}$ anti-PD-1 mAb was administered by i.p. injection (clone RPM1-14, BioXcell). In vivo neutralization of CD86 and/or CD80 was achieved by treating animals with CTLA-4-Ig (ORENCIA [abatacept], Bristol-Myers Squibb) or anti-CD80 mAb (clone 1G10, BioXcell) as specified in the Supplemental Methods. In preliminary experiments, the isotype control Abs were used in the control treatment groups.

Assessment of skin reaction on treated ears. Vehicle- or ABC-painted ears of WT and/or HLA-B ${ }^{*}$ 7:01-Tg animals were examined daily for signs of skin hypersensitivity and were photographed (EOS Rebel T5, Canon). Ear skin biopsy samples were used for histological and gene expression analyses as detailed in the Supplemental Methods.

Flow cytometry, cell sorting, and in vivo proliferation assays. Flow cytometry was used for the genotyping of mice, immune cell subset analysis by intracellular and/or surface marker staining, in vivo proliferation assays of $\mathrm{CD}^{+} \mathrm{T}$ lymphocytes, and $\mathrm{CD}^{+} \mathrm{T}$ cell sorting, as further detailed in the Supplemental Methods.

$\mathrm{CD}^{+}$and $\mathrm{CD}^{+}{ }^{+} \mathrm{T}$ lymphocytes were pregated on singlet live $\mathrm{CD}^{+}$cells; B cells were pregated on singlet $\mathrm{CD}^{-}$cells and identified

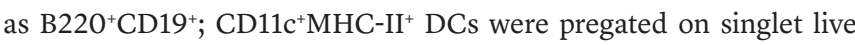
cells and identified as CD11 $\mathrm{c}^{+} \mathrm{I}-\mathrm{A}^{\mathrm{b}+}$ cells after gating out the $\mathrm{CD}^{+}$and $\mathrm{CD} 19^{+}$cells; and the DC subpopulation of $\mathrm{XCR} 1^{+}$cells was pregated on singlet live $\mathrm{CD} 11 \mathrm{c}^{+} \mathrm{I}-\mathrm{A}^{\mathrm{b}+}$ cells.

NanoString sample preparation and data analysis. NanoString nCounter gene expression profiling was performed on $\mathrm{CD}^{+} \mathrm{T}$ lymphocytes sorted from LN cells of individual mice treated for up to 10 days, as detailed in the Methods section Treatment of mice. After sorting, total RNA was extracted and hybridized with CodeSet and ProbeSet for 561 genes in the nCounter Mouse Immunology Panel plus 30 additional genes in a custom nCounter Panel-Plus and CodeSet-Plus (Supplemental Table 4) (all from Nanostring Technologies), according to the manufacturer's instructions. Details on the data analysis including gene set enrichment analysis (GSEA) are provided in the Supplemental Methods.

Statistics. Statistical analyses were performed using an unpaired, 2-tailed Student's $t$ test and 2-way or 1-way ANOVA with Tukey's multiple comparisons correction (GraphPad Prism 7.02, GraphPad Software). NanoString data analysis was performed using a 2-tailed Student's $t$ test with Welch's correction (nSolver, version 3.0; NanoString Technologies). A P value of less than 0.05 was considered statistically significant.

Study approval. All experiments involving live animals were performed in accordance with the guidelines set forth in the Public Health Service Policy on the Humane Care and Use of Laboratory Animals and were approved by the IACUCs of the US FDA (protocol number 2017-11) and the NIAID, NIH (protocol number LI40).

\section{Author contributions}

MC, MP, DHM, and MAN conceived, planned, and supervised the experiments. MET, LFB, KN, and DHM generated the HLA-B ${ }^{\star} 57: 01-$ Tg mice. MC, MP, KG, MET, and SG performed experiments. MY, GR, ADA, LJ, EM, and SA provided technical help. MC and MP analyzed the data. MC prepared the final figures and wrote the manuscript. MC, MP, KN, DHM, and MAN edited and reviewed the manuscript.

\section{Acknowledgments}

We thank Janet Woodcock, Director of the Center for Drug Evaluation and Research (CDER, FDA) for her continued support of this project. The authors wish to thank Jill Ascher, Mary Belcher, and the personnel of the animal facility of the US FDA's Division of Veterinary Medicine for care of the mice. We also thank Hugh McFarland (CDER, FDA) for help with cell irradiation, Mark Kukuruga and the Center for Biologics Evaluation and Research flow cytometry core facility at the FDA White Oak campus for help with cell sorting, and Ethan M. Shevach (National Institute of Allergy and Infectious Diseases, NIH) for his comments on the manuscript. This work was supported by the FDA Intramural Research Program. DHM's group is supported by the Intramural Research Program of the NIAID, NIH.

Address correspondence to: Marco Cardone, DBRR III/OBP/ OPQ/CDER, U.S. Food and Drug Administration, 10903 New Hampshire Avenue, Silver Spring, Maryland 20993, USA. Phone: 240.402.9419; Email: Marco.Cardone@fda.hhs.gov. David H. Margulies, Laboratory of Immune System Biology, NIAID, National Institutes of Health, 9000 Rockville Pike, Bethesda, Maryland 20892, USA. Phone: 301.496.6429; Email: DMARGULIES@ niaid.nih.gov. Michael A. Norcross, DBRR III/OBP/OPQ/CDER, U.S. Food and Drug Administration, 10903 New Hampshire Avenue, Silver Spring, Maryland 20993, USA. Phone: 240.402.8338; Email: michael.norcross@fda.hhs.gov.

MET's present address is: Office of AIDS Research, DPCPSI, OD, NIH, Bethesda, Maryland, USA. 
1. Pavlos R, et al. T cell-mediated hypersensitivity reactions to drugs. Annu Rev Med. 2015;66:439-454

2. Hetherington $S$, et al. Genetic variations in HLA-B region and hypersensitivity reactions to abacavir. Lancet. 2002;359(9312):1121-1122.

3. Mallal S, et al. Association between presence of HLA-B*5701, HLA-DR7, and HLA-DQ3 and hypersensitivity to HIV-1 reverse-transcriptase inhibitor abacavir. Lancet. 2002;359(9308):727-732.

4. Daly AK, et al. HLA-B*5701 genotype is a major determinant of drug-induced liver injury due to flucloxacillin. Nat Genet. 2009;41(7):816-819.

5. Xu CF, et al. HLA-B*57:01 confers susceptibility to pazopanib-associated liver injury in patients with cancer. Clin Cancer Res. 2016;22(6):1371-1377.

6. Hetherington $S$, et al. Hypersensitivity reactions during therapy with the nucleoside reverse transcriptase inhibitor abacavir. Clin Ther. 2001;23(10):1603-1614.

7. Phillips EJ, Sullivan JR, Knowles SR, Shear NH. Utility of patch testing in patients with hypersensitivity syndromes associated with abacavir. AIDS. 2002;16(16):2223-2225.

8. Martin AM, et al. Predisposition to abacavir hypersensitivity conferred by HLA-B 5701 and a haplotypic Hsp70-Hom variant. Proc Natl Acad Sci U S A. 2004;101(12):4180-4185.

9. Martin AM, et al. Immune responses to abacavir in antigen-presenting cells from hypersensitive patients. AIDS. 2007;21(10):1233-1244.

10. Chessman D, et al. Human leukocyte antigen class I-restricted activation of $\mathrm{CD} 8^{+} \mathrm{T}$ cells provides the immunogenetic basis of a systemic drug hypersensitivity. Immunity. 2008;28(6):822-832.

11. Adam J, Eriksson KK, Schnyder B, Fontana S, Pichler WJ, Yerly D. Avidity determines T-cell reactivity in abacavir hypersensitivity. Eur J Immunol. 2012;42(7):1706-1716.

12. Bell CC, et al. T-cells from HLA-B*57:01+ human subjects are activated with abacavir through two independent pathways and induce cell death by multiple mechanisms. Chem Res Toxicol. 2013;26(5):759-766.

13. Adam J, et al. Abacavir induced $T$ cell reactivity from drug naïve individuals shares features of allo-immune responses. PLoS One. 2014;9(4):e95339.

14. Lucas A, et al. Abacavir-reactive memory T cells are present in drug naive individuals. PLoS One. 2015;10(2):e0117160.

15. FDA. Information on Abacavir (marketed as Ziagen) and Abacavir-containing Medications. FDA Website. https://www.fda.gov/Drugs/DrugSafety/ ucm094302.htm. Updated July 8, 2015. Accessed April 23, 2018.

16. Mallal S, et al. HLA-B 5701 screening for hypersensitivity to abacavir. $N$ Engl J Med 2008;358(6):568-579.

17. Saag M, et al. High sensitivity of human leukocyte antigen- $\mathrm{b}^{*} 5701$ as a marker for immunologically confirmed abacavir hypersensitivity in white and black patients. Clin Infect Dis. 2008;46(7):1111-1118

18. Norcross MA, et al. Abacavir induces loading of novel self-peptides into HLA-B*57: 01: an autoimmune model for HLA-associated drug hypersensitivity. AIDS. 2012;26(11):F21-F29.
19. Illing PT, et al. Immune self-reactivity triggered by drug-modified HLA-peptide repertoire. Nature. 2012;486(7404):554-558.

20. Ostrov DA, et al. Drug hypersensitivity caused by alteration of the MHC-presented selfpeptide repertoire. Proc Natl Acad Sci U S A. 2012;109(25):9959-9964.

21. Yerly D, et al. Structural elements recognized by abacavir-induced T cells. Int J Mol Sci. 2017;18(7):E1464.

22. Klatt NR, Funderburg NT, Brenchley JM. Microbial translocation, immune activation, and HIV disease. Trends Microbiol. 2013;21(1):6-13.

23. Schietinger A, Greenberg PD. Tolerance and exhaustion: defining mechanisms of $\mathrm{T}$ cell dysfunction. Trends Immunol. 2014;35(2):51-60.

24. Attanasio J, Wherry EJ. Costimulatory and coinhibitory receptor pathways in infectious disease. Immunity. 2016;44(5):1052-1068.

25. Vignali DA, Collison LW, Workman CJ. How regulatory T cells work. Nat Rev Immunol. 2008;8(7):523-532.

26. Irwin MJ, Heath WR, Sherman LA. Speciesrestricted interactions between $\mathrm{CD} 8$ and the $\alpha 3$ domain of class I influence the magnitude of the xenogeneic response. JExp Med. 1989;170(4):1091-1101.

27. Safford M, et al. Egr-2 and Egr-3 are negative regulators of T cell activation. Nat Immunol. 2005;6(5):472-480.

28. Wherry EJ, et al. Molecular signature of $\mathrm{CD} 8^{+} \mathrm{T}$ cell exhaustion during chronic viral infection. Immunity. 2007;27(4):670-684

29. West EE, et al. Tight regulation of memory CD8(+) T cells limits their effectiveness during sustained high viral load. Immunity. 2011;35(2):285-298.

30. Kaech SM, Hemby S, Kersh E, Ahmed R. Molecular and functional profiling of memory CD8 T cell differentiation. Cell. 2002;111(6):837-851.

31. Luckey CJ, Bhattacharya D, Goldrath AW, Weissman IL, Benoist C, Mathis D. Memory $T$ and memory $B$ cells share a transcriptional program of self-renewal with long-term hematopoietic stem cells. Proc Natl Acad Sci U S A. 2006;103(9):3304-3309.

32. Oestreich KJ, Yoon H, Ahmed R, Boss JM. NFATc1 regulates PD-1 expression upon T cell activation. JImmunol. 2008;181(7):4832-4839.

33. Miao T, et al. Egr 2 and 3 control adaptive immune responses by temporally uncoupling expansion from $\mathrm{T}$ cell differentiation. J Exp Med. 2017;214(6):1787-1808

34. Olenchock BA, et al. Disruption of diacylglycerol metabolism impairs the induction of $\mathrm{T}$ cell anergy Nat Immunol. 2006;7(11):1174-1181.

35. Schildknecht A, et al. FoxP3 ${ }^{+}$regulatory T cells essentially contribute to peripheral $\mathrm{CD} 8^{+} \mathrm{T}$-cell tolerance induced by steady-state dendritic cells. Proc Natl Acad Sci U S A. 2010;107(1):199-203.

36. Muth S, Schütze K, Schild H, Probst HC. Release of dendritic cells from cognate $\mathrm{CD} 4^{+} \mathrm{T}$-cell recognition results in impaired peripheral tolerance and fatal cytotoxic T-cell mediated autoimmunity. Proc Natl Acad Sci U S A. 2012;109(23):9059-9064.

37. Kim JM, Rasmussen JP, Rudensky AY. Regulatory $\mathrm{T}$ cells prevent catastrophic autoimmunity throughout the lifespan of mice. Nat Immunol.
2007;8(2):191-197.

38. Bolton HA, et al. Selective Treg reconstitution during lymphopenia normalizes DC costimulation and prevents graft-versus-host disease. J Clin Invest. 2015;125(9):3627-3641.

39. Haile ST, et al. Tumor cell programmed death ligand 1-mediated $\mathrm{T}$ cell suppression is overcome by coexpression of CD80. Jimmunol. 2011;186(12):6822-6829.

40. Haile ST, Dalal SP, Clements V, Tamada K, Ostrand-Rosenberg S. Soluble CD80 restores $\mathrm{T}$ cell activation and overcomes tumor cell programmed death ligand 1-mediated immune suppression. J Immunol. 2013;191(5):2829-2836.

41. Haile ST, Horn LA, Ostrand-Rosenberg S. A soluble form of CD80 enhances antitumor immunity by neutralizing programmed death ligand- 1 and simultaneously providing costimulation. Cancer Immunol Res. 2014;2(7):610-615.

42. Illing PT, Mifsud NA, Purcell AW. Allotype specific interactions of drugs and HLA molecules in hypersensitivity reactions. Curr Opin Immunol. 2016;42:31-40.

43. Jameson SC, Lee YJ, Hogquist KA. Innate memory T cells. Adv Immunol. 2015;126:173-213.

44. Li S, et al. The transcription factors Egr2 and Egr3 are essential for the control of inflammation and antigen-induced proliferation of $\mathrm{B}$ and $\mathrm{T}$ cells. Immunity. 2012;37(4):685-696.

45. Duraiswamy J, et al. Phenotype, function, and gene expression profiles of programmed death-1(hi) CD8 T cells in healthy human adults. JImmunol. 2011;186(7):4200-4212.

46. Tsushima F, et al. Interaction between $\mathrm{B} 7-\mathrm{H} 1$ and PD-1 determines initiation and reversal of T-cell anergy. Blood. 2007;110(1):180-185.

47. Chikuma S, et al. PD-1-mediated suppression of IL-2 production induces $\mathrm{CD} 8^{+} \mathrm{T}$ cell anergy in vivo. J Immunol. 2009;182(11):6682-6689.

48. Sakaguchi S. Naturally arising Foxp3-expressing $\mathrm{CD} 25^{+} \mathrm{CD} 4^{+}$regulatory $\mathrm{T}$ cells in immunological tolerance to self and non-self. Nat Immunol. 2005;6(4):345-352.

49. Kalia V, Penny LA, Yuzefpolskiy Y, Baumann FM, Sarkar S. Quiescence of memory CD8(+) $\mathrm{T}$ cells is mediated by regulatory $\mathrm{T}$ cells through inhibitory receptor CTLA-4. Immunity. 2015;42(6):1116-1129.

50. Provine NM, et al. Immediate dysfunction of vaccine-elicited $\mathrm{CD} 8^{+} \mathrm{T}$ cells primed in the absence of $\mathrm{CD} 4^{+} \mathrm{T}$ cells. JImmunol. 2016;197(5):1809-1822.

51. Lahl K, et al. Selective depletion of Foxp $3^{+}$ regulatory $\mathrm{T}$ cells induces a scurfy-like disease. J Exp Med. 2007;204(1):57-63.

52. Poitrasson-Rivière $M$, Bienvenu $B$, Le Campion A, Bécourt C, Martin B, Lucas B. Regulatory $\mathrm{CD}^{+} \mathrm{T}$ cells are crucial for preventing CD8 T cell-mediated autoimmunity. J Immunol. 2008;180(11):7294-7304.

53. Cederbom L, Hall H, Ivars F. $\mathrm{CD} 4{ }^{+} \mathrm{CD} 25^{+}$regulatory $\mathrm{T}$ cells down-regulate co-stimulatory molecules on antigen-presenting cells. Eur J Immunol. 2000;30(6):1538-1543.

54. Misra N, Bayry J, Lacroix-Desmazes S, Kazatchkine MD, Kaveri SV. Cutting edge: human $\mathrm{CD} 4^{+} \mathrm{CD} 25^{+} \mathrm{T}$ cells restrain the maturation and antigen-presenting function of dendritic cells. 
JImmunol. 2004;172(8):4676-4680.

55. Eickhoff S, et al. Robust anti-viral immunity requires multiple distinct $\mathrm{T}$ cell-dendritic cell interactions. Cell. 2015;162(6):1322-1337.

56. Hor JL, Whitney PG, Zaid A, Brooks AG, Heath WR, Mueller SN. Spatiotemporally distinct interactions with dendritic cell subsets facilitates $\mathrm{CD}^{+}$and $\mathrm{CD}^{+} \mathrm{T}$ cell activation to localized viral infection. Immunity. 2015;43(3):554-565.

57. Boesteanu AC, Katsikis PD. Memory T cells need CD28 costimulation to remember. Semin Immunol. 2009;21(2):69-77.

58 . Montoya M, et al. Type I interferons produced by dendritic cells promote their phenotypic and functional activation. Blood. 2002;99(9):3263-3271.

59. Gallucci S, Lolkema M, Matzinger P. Natural adjuvants: endogenous activators of dendritic cells. Nat Med.1999;5(11):1249-1255.

60. Toksoy A, et al. Potent NLRP3 inflammasome activation by the HIV reverse transcriptase inhibitor abacavir. J Biol Chem. 2017;292(7):2805-2814.
61. Christensen AD, Skov S, Kvist PH, Haase C. Depletion of regulatory $\mathrm{T}$ cells in a hapteninduced inflammation model results in prolonged and increased inflammation driven by $\mathrm{T}$ cells. Clin Exp Immunol. 2015;179(3):485-499.

62. Nattrass R, et al. Activation of flucloxacillinspecific $\mathrm{CD}^{+} \mathrm{T}$-cells with the potential to promote hepatocyte cytotoxicity in a mouse model. Toxicol Sci. 2015;146(1):146-156.

63. Gibson A, et al. The effect of inhibitory signals on the priming of drug hapten-specific T cells that express distinct $\mathrm{V} \beta$ receptors. J Immunol. 2017;199(4):1223-1237.

64. Gibson A, et al. Negative regulation by PD-L1 during drug-specific priming of IL-22-secreting $\mathrm{T}$ cells and the influence of PD-1 on effector T cell function. JImmunol. 2014;192(6):2611-2621.

65. Tincati C, Douek DC, Marchetti G. Gut barrier structure, mucosal immunity and intestinal microbiota in the pathogenesis and treatment of HIV infection. AIDS Res Ther. 2016;13:19.
66. Susukida T, et al. Evaluation of immunemediated idiosyncratic drug toxicity using chimeric HLA transgenic mice. Arch Toxicol. 2018;92(3):1177-1188.

67. Song B, Aoki S, Liu C, Susukida T, Ito K. An animal model of abacavir-induced HLA-mediated liver injury. Toxicol Sci. 2018;162(2):713-723.

68. Pircher $\mathrm{H}$, et al. T cell tolerance to Mlsa encoded antigens in $\mathrm{T}$ cell receptor V $\beta 8.1$ chain transgenic mice. ЕMBO J. 1989;8(3):719-727.

69. Aaronson SA. Oncogenes and the Molecular Origins of Cancer. Robert A. Weinberg, Ed. Cold Spring Harbor Laboratory Press, Cold Spring Harbor, NY, 1989. xii, 367 pp., illus. Paper, \$55. Cold Spring Harbor Monograph 18. Science. 1990;249(4973):1177-1178.

70. Drouet M, Aussel L, Drenou B, Fauchet R. Quantification and molecular analysis of plasmatic HLA-BCw molecules with a locus B and Cw HLA specific $\mathrm{mAb}$ (B1.23.2 mAb). Eur J Immunogenet. 1995;22(5):363-370. 